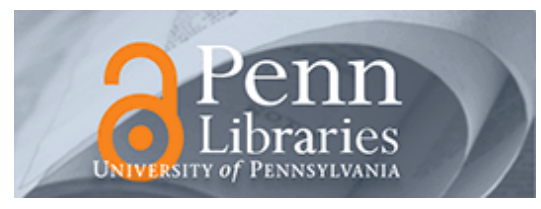

University of Pennsylvania

ScholarlyCommons

Business Economics and Public Policy Papers

Wharton Faculty Research

2013

\title{
Perverse Reverse Price Competition: Average Wholesale Prices and Medicaid Pharmaceutical Spending
}

Abby Alpert

Mark Duggan

University of Pennsylvania

Judith K. Hellerstein

Follow this and additional works at: https://repository.upenn.edu/bepp_papers

Part of the Business Commons, and the Public Economics Commons

\section{Recommended Citation}

Alpert, A., Duggan, M., \& Hellerstein, J. K. (2013). Perverse Reverse Price Competition: Average Wholesale Prices and Medicaid Pharmaceutical Spending. Journal of Public Economics, 108 (C), 44-62.

http://dx.doi.org/10.3386/w19367

This paper is posted at ScholarlyCommons. https://repository.upenn.edu/bepp_papers/129

For more information, please contact repository@pobox.upenn.edu. 


\title{
Perverse Reverse Price Competition: Average Wholesale Prices and Medicaid Pharmaceutical Spending
}

\begin{abstract}
Generic drugs comprise an increasing share of total prescriptions dispensed in the U.S., rising from nearly $50 \%$ in 1999 to $75 \%$ in 2009 . The generic drug market has typically been viewed at the wholesale level as a competitive market with price approaching marginal costs. However, the large presence of third party payers as final purchasers may distort prices at the retail level relative to what a standard model of price competition would predict. In this paper, we investigate how generic drug producers compete in the presence of the procurement rules of the Medicaid program. Medicaid reimbursement to pharmacies, like that of other payers, is based on a benchmark price called the average wholesale price (AWP). The AWP is reported by generic producers themselves, and until recently has been subject to essentially no independent verification. As a result, generic producers have had an incentive to compete for pharmacy market share by reporting AWPs that exceed actual average wholesale prices, as this "spread" leads to larger pharmacy profits. In 2000, after a federal government audit of actual wholesale prices of generic products, states were advised to reduce Medicaid reimbursement by as much as $95 \%$ for about 400 generic and off-patent drug products. We use variation induced by the timing of this policy along with its differential impact on drug products' Medicaid reimbursement to estimate the impact of this exogenous price change on the market share of targeted products. Our findings indicate that pharmacies did respond to the perverse incentives of the Medicaid program by dispensing products with the highest AWPs.

Overall, the Medicaid market share fell by about $45 \%$ for targeted drug products as a result of the policy.
\end{abstract}

\section{Keywords}

medicaid, reimbursement policy, prescription drugs, competition

\section{Disciplines}

Business | Public Economics 


\title{
Perverse Reverse Price Competition: Average Wholesale Prices and Medicaid Pharmaceutical Spending
}

\author{
Abby Alpert \\ University of California, \\ Irvine \\ aealpert@uci.edu
}

\author{
Mark Duggan \\ Wharton and NBER \\ mduggan@wharton.upenn.edu
}

\author{
Judith K. Hellerstein \\ University of Maryland and \\ NBER \\ hellerst@econ.umd.edu
}

August 2013

\begin{abstract}
Generic drugs comprise an increasing share of total prescriptions dispensed in the U.S., rising from nearly 50 percent in 1999 to 75 percent in 2009. The generic drug market has typically been viewed at the wholesale level as a competitive market with price approaching marginal costs. However, the large presence of third party payers as final purchasers may distort prices at the retail level relative to what a standard model of price competition would predict. In this paper, we investigate how generic drug producers compete in the presence of the procurement rules of the Medicaid program. Medicaid reimbursement to pharmacies, like that of other payers, is based on a benchmark price called the average wholesale price (AWP). The AWP is reported by generic producers themselves, and until recently has been subject to essentially no independent verification. As a result, generic producers have had an incentive to compete for pharmacy market share by reporting AWPs that exceed actual average wholesale prices, as this "spread" leads to larger pharmacy profits. In 2000, after a federal government audit of actual wholesale prices of generic products, states were advised to reduce Medicaid reimbursement by as much as 95\% for about 400 generic and off-patent drug products. We use variation induced by the timing of this policy along with its differential impact on drug products' Medicaid reimbursement to estimate the impact of this exogenous price change on the market share of targeted products. Our findings indicate that pharmacies did respond to the perverse incentives of the Medicaid program by dispensing products with the highest AWPs. Overall, the Medicaid market share fell by about $45 \%$ for targeted drug products as a result of the policy.
\end{abstract}

\footnotetext{
We are grateful for helpful comments from three anonymous referees, the editor Joseph Doyle, Ernie Berndt, Guy David, Mireille Jacobson, Andrew Mulcahy, David Powell, and seminar and conference participants at the American Society of Health Economists, Columbia University, RAND, University of California-Riverside, University of Oregon, and Wharton. We thank Brian Collopy and Samuel Hollin for excellent research assistance. Alpert gratefully acknowledges financial support from the RAND Bing Center for Health Economics and Duggan thanks the Dean's Research Fund at the Wharton School for financial support. All errors are our own.
} 


\section{Introduction}

Generic drugs comprise an increasing share of total prescriptions dispensed in the U.S., rising from nearly 50 percent in 1999 to 75 percent in 2009 (Berndt and Aitken, 2010). The generic drug market has typically been viewed at the wholesale level ${ }^{1}$ as approximately competitive, with price approaching marginal costs. Largely as a result of this, the widespread availability of generic drugs is generally perceived as extremely beneficial to consumers and to those who bear the burden of paying for these treatments. However, at the retail level, generic prices may well exceed marginal cost, even by a wide margin. One important aspect of the generic drug market that has been largely unexplored is how drug procurement by the government and private insurers impacts competition among generic drug manufacturers. In particular, procurement rules may distort retail generic drug prices away from marginal cost by perversely rewarding higher-priced generics with greater market share.

The main objective of this paper is to investigate how generic drug manufacturers compete in the presence of the procurement rules of the Medicaid program. We examine the impact of procurement on competition by evaluating how drug purchasing patterns responded to a plausibly exogenous negative price shock generated by a significant government intervention. During the period under study, Medicaid accounted for nearly 20\% of all prescription drug expenditures in the U.S. Thus, distortions in the market for drugs purchased by Medicaid have potentially large impacts on overall drug spending, and health care spending more generally.

How might procurement distort generic competition? Consider a stylized market without procurement. In the absence of government and private insurance, all consumers pay pharmacies (or other generic dispensers) in cash for drugs purchased. Consumers are indifferent between bioequivalent generic drugs that are produced by one manufacturer versus another ${ }^{2}$, and thus purchase the drug from the pharmacy with the lowest price. In turn, pharmacies stock and dispense the version of the generic drug that is least costly, choosing among possibly dozens of manufacturers. Competition among generic manufacturers for pharmacy market share, and competition among pharmacies for consumers, drives the equilibrium price down to marginal cost at both the wholesale and retail levels.

\footnotetext{
${ }^{1}$ Wholesale refers to transactions between manufacturers (or wholesalers) and pharmacies and retail refers to transactions between pharmacies and final purchasers (e.g. consumers or insurers).

${ }^{2}$ Since generic drugs are regulated to be identical in their chemical structure and strength, a specific manufacturer is rarely designated in a physician's written prescription for a generic drug.
} 
The actual market for generic drugs differs from this textbook scenario for two main reasons. First, there are very few cash-paying consumers in the pharmaceutical market. The last few decades have seen a dramatic rise in prescription drug insurance coverage. The fraction of drug spending paid for by public and private payers has grown from 34\% in 1980 to nearly 80\% in 2000, and 92\% in 2010 (Berndt and Aitken, 2010). Thus cash-paying consumers currently account for only $8 \%$ of payments. Insured consumers are virtually price insensitive with respect to choosing among different manufacturers of a generic drug, since they typically pay a copay that is fixed across equivalent generic drugs. Consequently, consumers play little role in generic price competition, leaving public and private payers - who account for the lion's share of payments to pharmacies - as the main driving force.

Second, the largest purchasers of generic drugs - public and private insurers - do not pay pharmacies' posted prices. Government and private insurers set their own rules to determine how much to reimburse pharmacies for drugs that they dispense. For Medicaid, like other payers, reimbursement for each prescription has typically been based on a benchmark price called the average wholesale price (AWP), ${ }^{3}$ which is published in several pricing catalogues. For each product, this list price is reported to the catalogues by generic manufacturers themselves, and until recent years has been subject to essentially no independent verification of its resemblance to the actual average price that pharmacies pay manufacturers to acquire drugs. As a result, generic manufacturers have had an incentive to compete for pharmacy market share by reporting AWPs that are much greater than average prices actually paid by pharmacies, as higher "spreads” lead to larger pharmacy profits. Put another way, since higher AWPs generate higher reimbursement for pharmacies, manufacturers might compete to report higher and higher AWPs in order to induce pharmacies to stock their drug rather than a competitor's drug. This may partially explain why differences between published and actual average prices of more than $1000 \%$ have been uncovered in recent government audits for some generic drugs. Thus, competition among manufacturers may increase rather than reduce the prices on which Medicaid reimbursement is based, leading to inflated Medicaid spending.

\footnotetext{
${ }^{3}$ A few states use the Wholesale Acquisition Cost (WAC) or the minimum of the WAC and AWP as their reimbursement benchmark. In 2000, the year of the policy intervention we study, Massachusetts and Rhode Island were the only two states using the WAC as their primary reimbursement benchmark (National Pharmaceutical Council, 2000).
} 
To empirically investigate the impact of Medicaid procurement on price competition, we examine an intervention that caused a sharp decline in price for a well-defined set of generic drugs. In the late 1990s, an investigation by the Department of Justice (DOJ) and the National Association of Medicaid Fraud Control Units (NAMFCU) "revealed a pattern of misrepresentations by some drug manufacturers of the average wholesale prices and wholesale acquisition costs of certain of their products." ${ }^{4}$ As a result of this audit, in May 2000, states were advised to reduce the AWP used to reimburse pharmacies by as much as $95 \%$ for approximately 400 generic and off-patent injectable, infusion, and inhalation drug products. This intervention provides a rare opportunity to study price competition because unlike other payment reforms, such as the Medicare Modernization Act which lowered prices for all physician-administered drugs (which are covered by Medicare Part B), this policy differentially lowered price for only a select set of drugs within classes of bioequivalent products. Thus we can compare changes in pharmacy purchases before and after the price change for targeted generic drugs and their bioequivalent competitors to estimate pharmacy demand responses and infer manufacturers' pricing behavior. For example, in the market for Acetylcysteine, the DOJ recommended that Medicaid lower the AWP to the audited price for several products produced by three manufacturers, but did not make any price recommendations for the other seven manufacturers of this drug. Finding shifts in purchases away from targeted drugs towards their competitors as the relative price of targeted drugs declined would be evidence that pharmacies respond to the perverse incentives of the Medicaid program by stocking products with relatively high AWPs.

Using more than a decade of Medicaid State Drug Utilization Data from the Centers for Medicare and Medicaid Services (CMS), we demonstrate that actual reimbursement per prescription purchased declined substantially for targeted drugs following the 2000 DOJ recommendations, relative to competitor products whose AWPs were not targeted by the DOJ. We also find evidence of a decline in the number of targeted drug prescriptions dispensed to Medicaid patients by pharmacies and an increase in the number of competitor drugs dispensed. Overall, the market share, measured in terms of Medicaid prescriptions dispensed, for targeted drugs fell by about $45 \%$ through 2004, implying that pharmacies substituted away from drug products whose prices were reduced.

\footnotetext{
${ }^{4}$ Office of the Attorney General, Medicaid Fraud Control Unit, State of New York, 2000.
} 
In general, our results show that pharmacies respond to the incentives inherent in AWPbased reimbursement by dispensing drugs in a manner consistent with profit-maximizing behavior, but inconsistent with a standard model of price competition in which lower-priced drugs capture higher market share. Medicaid procurement incentives have led at least some generic manufacturers to compete by (sometimes vastly) overstating AWPs, which can markedly reduce the cost savings to consumers or insurers from using generic drugs.

The remainder of the paper proceeds as follows. Section 2 provides detailed background about the AWP and related literature. Section 3 discusses the DOJ intervention. Section 4 describes the data and sample restrictions. Section 5 outlines the empirical framework and presents the descriptive statistics and results. Section 6 concludes.

\section{Background}

\subsection{AWP Basics}

AWP-based reimbursement was first introduced by California's Medicaid program in 1969, at a time when public and private insurers were just beginning to pay for prescription drugs (insurers accounted for only $15 \%$ of total drug spending in that year). ${ }^{5}$ Its predecessor, "cost-based" reimbursement, reimbursed pharmacies the exact amount they were charged by manufacturers to purchase the drug plus a fixed dispensing fee to cover labor and capital costs. This method led to a multitude of reimbursement amounts for identical products. More importantly, since pharmacies would receive the same (zero) profit margin from reimbursement regardless of their acquisition costs, drug manufacturers could in turn set high prices without reducing pharmacies' demand for their product.

In contrast, the AWP approach provided an opportunity for pharmacies to profit from Medicaid reimbursement through the existence of a "spread.” The spread is the difference between the reimbursement amount (which is computed as a fixed proportion of each drug's AWP) and the pharmacy's actual acquisition costs. A positive (negative) spread is a profit (loss) for the pharmacy. Policymakers anticipated that pharmacies would seek to maximize this spread by searching for the lowest priced versions of generic drugs. In turn, this in theory would induce price competition among manufacturers, which would thereby allow Medicaid to lower their reimbursement amounts over time. Other states and private insurers soon adopted California's

\footnotetext{
${ }^{5}$ Calculations from CMS National Health Accounts (2011).
} 
model and publishers such as the Red Book, Blue Book, Medi-Span, and First Data Bank, entered the market to meet the demand for data on average wholesale prices. (See for example, Kolassa, 1994; Kolassa, 1997; Berndt and Newhouse, 2012; and Danzon et al., 2005; for a more detailed summary of the history of the AWP).

A typical AWP-based reimbursement rule used by public and private payers is defined as follows. For each drug product $j$ dispensed to a recipient of insurance type $i$, the pharmacy receives a reimbursement amount equal to ${ }^{6}$ :

$$
\text { Reimbursement }_{i j}=\left(1-\alpha_{i}\right) \cdot A W P_{j}+\text { DispensingFee }_{i}
$$

Where $0 \leq \alpha_{i} \leq 1$. Thus, a pharmacy earns a profit of $\Pi_{i j}=$ Reimbursement $_{i j}-p_{j}^{a}$, where $p_{j}^{a}$ is the acquisition cost of drug $j$ from the manufacturer.

Given that $\alpha_{i}$ and the dispensing fee are fixed across drugs, the $A W P_{j}$ and $p_{j}^{a}$ are the crucial factors governing whether pharmacies choose to stock one generic version over another. In pricing catalogues, the AWP is reported for each drug at the level of the National Drug Code (NDC). The NDC is a unique eleven-digit identification number assigned by the FDA to every drug product distributed in the U.S. The first 5 digits uniquely identify the manufacturer, the next 4 digits identify the product code (which include the strength, dosage form, and formulation of the drug), and the final 2 digits identify the package size and type. Thus a single NDC code uniquely defines one drug produced by one particular manufacturer and is denoted by $j$ in the equation above. In the case of generic drugs, the NDC can distinguish between identical, bioequivalent drugs that are produced by different manufacturers because each version will have a unique NDC.

For the Medicaid program, there are a few additional caveats regarding the parameters of the reimbursement rule. First, $\alpha_{i}$ may vary across brand name and generic drugs (the former is typically smaller). ${ }^{7}$ Second, the AWP is sometimes replaced by a lower, government-determined price for certain generic drugs. These prices are known as the Federal Upper Limit (FUL) or the Maximum Allowable Cost (MAC). FULs, which were first established by the federal

\footnotetext{
${ }^{6}$ This rule generates what is known as the "Estimated Acquisition Cost" (EAC) and reimbursement is based on the minimum of the EAC or "Usual and Customary Charge" (U\&C).

${ }^{7}$ See, for example, state Medicaid reimbursement rules available on CMS website: http://www.medicaid.gov/Medicaid-CHIP-Program-Information/By-Topics/Benefits/Prescription-Drugs/StatePrescription-Drug-Resources.html
} 
government in 1987, denote the maximum price at which the Medicaid program will reimburse pharmacies for certain drugs. Generic drugs that have three or more manufacturers are frequently subject to these limits, which have been traditionally set at 150 percent of the lowest published AWP among all equivalent versions of the drug (KFF, 2002). Over 200 drugs were on the FUL list during the study period (OIG, 2001), though reports by the OIG suggest that not all eligible generic drugs receive FULs (OIG, 2004a, 2004b). MACs are similar to reimbursement limits for generic drugs that are set by each individual state's Medicaid program. These limits tend to be wider in scope and are more aggressive than FULs (Abramson, 2004). Third, there is also variation in the $\alpha_{i}$ and the dispensing fee across states: the Medicaid $\alpha_{i}$ ranged from 0.05 to 0.15 across states during the period under study (NPC, 2000). ${ }^{8}$ To the extent that any of these mechanisms do restrain prices, our results are net of these disciplinary devices.

\subsection{The AWP and Medicaid Procurement Incentives}

In the previous section we outlined the two main parameters governing transactions between payers, pharmacies, and manufacturers $\left(A W P_{j}\right.$ and $\left.p_{j}^{a}\right)$. In this section we briefly discuss how manipulation of the AWP can lead to a perverse form of price competition in which manufacturers compete to offer pharmacies the highest-priced version of a generic drug. We focus on the Medicaid program, but an analogous discussion can be applied to other payers including private insurers.

First, recall that pharmacies earn a profit from Medicaid reimbursement if it generates a positive "spread"-- that is, the reimbursement (which is proportional to the $A W P_{j}$ ) exceeds the cost that pharmacies pay to acquire the drug from the manufacturer $p_{j}^{a}$. Thus, when choosing among bioequivalent NDCs, pharmacies prefer to stock the NDC that generates the largest spread. In turn, manufacturers have an incentive to compete for pharmacy market share by offering the largest possible spread between $A W P_{j}$ and $p_{j}^{a}$. They can do so by bidding up the $A W P_{j}$ and bidding down the $p_{j}^{a}$.

\footnotetext{
${ }^{8} \mathrm{CMS}$ also requires that drug manufacturers pay rebates to pharmacies. For generic and off-patent brand name drugs, the rebate is calculated as 13 percent of AMP in 2013 (Section 2501(b) of the Affordable Care Act). Specific states may have yet other mechanisms in place, such as formularies, that go at least some way toward restraining Medicaid reimbursement of generic drugs.
} 
While it may have been the original intent of Medicaid's reimbursement policy that the AWP reflect an average of the actual prices that pharmacies pay manufacturers or wholesalers to acquire the drug, in practice, manufacturers self-report the $A W P_{j}$ to the pricing catalogues. These self-reports are not subject to any independent verification (GAO, 2002). Consequently, as the GAO (2002) explains, the Average Wholesale Price "is neither an average nor a price that wholesalers charge...it is a number that manufacturers derive using their own criteria; there are no requirements or conventions that AWP reflect the price of any actual sale of drugs by a manufacturer.” Thus, since this price can be easily manipulated, manufacturers have an incentive to compete for pharmacy market share by simply reporting higher and higher AWPs. ${ }^{9}$

In the presence of AWP-based Medicaid reimbursement rules, we would expect there to be a positive spread in equilibrium. A spread of zero $\left(A W P_{j}=p_{j}^{a}\right)$ is not sustainable, since if one manufacturer sets an $A W P_{j}$ such that $A W P_{j}=p_{j}^{a}$, then another firm can report $A W P_{j}^{\prime}$ $>A W P_{j}=p_{j}^{a}$ and capture the entire market, all else equal. Similarly, one manufacturer could set $p_{j}^{a^{\prime}}<p_{j}^{a}$ with a similar outcome. Thus, manufacturers may bid up the AWP and bid down $p_{j}^{a}$ to marginal costs. In other words, Medicaid reimbursement policies provide an incentive for manufacturers to compete on the pharmacy's profit margin, rather than on simply the acquisition price as a text book model of Bertrand price competition might predict. While this type of manufacturer competition may lead to close to marginal cost pricing in transactions between pharmacies and manufacturers (as described in, e.g., Berndt and Newhouse, 2012; Berndt. et al., 2011; Ching, 2010; Reiffen and Ward, 2005; Grabowski and Vernon, 1992), it may generate prices greatly exceeding marginal costs in transactions between pharmacies and purchasers (such as Medicaid and other private payers). ${ }^{10}$ Evidence from numerous audits of actual spreads discussed below supports the prediction that the AWP will be inflated for generic drugs (e.g. CBO, 2004; GAO, 2001; OIG, 2002). Consequently, while the widespread availability of generic drugs is still largely perceived as unambiguously beneficial to consumers and payers, the

\footnotetext{
${ }^{9}$ If the AWP reflected an average of the actual prices that pharmacies pay wholesalers, then increasing actual wholesale prices requires that the manufacturer trade off the gain from additional Medicaid purchases against the loss of purchases from other payers. In cases where Medicaid payments are a small share of sales, manufacturers may find it profit-maximizing to compete by bidding down the $p_{j}^{a}$ rather than bidding up the $A W P_{j}$.

${ }^{10}$ The threat of attracting regulatory attention presumably deters manufacturers from inflating the AWP to infinitely high levels.
} 
cost savings from these drugs may be substantially overstated if the incentives of the reimbursement system lead manufacturers to report inflated AWPs for many drugs. ${ }^{11}$

\subsection{Evidence of the Spread and Related Literature}

Numerous studies conducted by government agencies (e.g. CBO, 2004; GAO, 2001; OIG, 2002) have uncovered large spreads for brand and generic drugs which are consistent with the hypothesis outlined in section 2.2 above. In one particularly striking study, the Office of Inspector General, Department of Health and Human Services (2002) conducted an audit of approximately 200 randomly selected pharmacies in eight states to obtain 8,728 invoice prices for prescription drugs. The authors found that on average pharmacies' actual drug acquisition price was $83 \%$ of the published AWP for brand name drugs, 56\% of the AWP for generic drugs without an FUL, and 28\% of the AWP for drugs with an FUL. It is interesting to note that the AWP was more inflated for generic drugs than brands ${ }^{12}$, and even drugs subject to FULs (typically the least concentrated markets with 3 or more manufacturers) had substantially inflated AWPs. If pharmacies' demand responds positively to the spread, increasing levels of competition among manufacturers could lead to increases in Medicaid drug spending.

In related studies, government audits have also uncovered large profit margins for physician-administered drugs (e.g. chemotherapy) under reimbursement rules for Medicare Part B. Before the Medicare Modernization Act was implemented in 2005, Medicare drug reimbursement to physicians was based on the same AWP-based payment rule as in the Medicaid program. ${ }^{13}$ In one Government Accountability Office audit (2001), physician’s average acquisition prices ranged from $66 \%$ to $87 \%$ of the AWP for a sample of the highest volume physician-administered drugs. Some oncology drugs could be purchased by physicians for as low as $15 \%$ of the AWP. Since physicians can substitute between therapeutically similar treatments for patients (brand and generic drugs alike), manufacturers of oncology drugs

\footnotetext{
${ }^{11}$ The retail market for generics also may not be fully competitive for reasons beyond AWP pricing. Berndt and Newhouse (2012) and Berndt et al., 2011, note that market power of certain retail pharmacies and pharmacy benefit managers may serve to restrain price competition at the retail level.

${ }^{12}$ The smaller spreads for brands relative to generics may also help accelerate the use of generic drugs, since pharmacies may earn greater profits from generic drugs than from branded drugs.

${ }^{13}$ Shea, et al. 2008 and Jacobson, et al. 2010 find that Medicare Part B's switch from AWP to ASP resulted in changes in chemotherapy treatment patterns, but no reduction in the likelihood of treatment or wait times for the drugs included in the studies.
} 
compete for physician market share in an analogous way that manufacturers of generic drugs compete for pharmacy market share.

While the issue of AWP inflation has received considerable attention in government reports and a series of recent lawsuits filed by CMS, it has not been explored in the academic literature. The most similar study to the present one is Duggan and Scott-Morton (2006) which examines the impact of Medicaid procurement on prices for brand name drugs. ${ }^{14}$ However, in contrast to that paper, we focus on generic drugs. The case for generics differs from the case for brands because Medicaid procurement distorts generic prices through its impact on pharmacy purchasing incentives. Pharmacies play an important and often overlooked role in driving price competition among multiple source drugs, yet relative to hospitals, physicians, nursing homes, and other providers, pharmacy behavior has received very little attention in the health economics literature. While pharmacies cannot automatically substitute between different brand name drugs, they may choose among potentially dozens of suppliers to determine which version of a generic drug to stock and dispense. Thus, generic manufacturers compete for pharmacy market share, whereas brand manufacturers compete for consumers and physicians who influence how prescriptions are written.

A second related literature examines the impact of reimbursement rules more broadly on real (e.g. Gruber et al, 1999) and nominal (e.g. Dafny, 2005) health care utilization. This large literature documents evidence from many contexts of substitution by providers towards procedures and services that are more generously reimbursed. For example, Gruber et al. (1999) shows that variation in the Medicaid reimbursement differential between Cesarean and normal childbirth across states leads to an increased rate of Cesarean births in states with larger reimbursement differentials. Dafny (2005) finds that differentials in Medicare reimbursement by the severity of diagnosis lead hospitals to falsely recode patients' diagnoses to the most profitable, high severity codes. While reimbursement differentials that distort actual treatment decisions could potentially have negative health consequences, distortions in simply the choice of manufacturers for generic drugs will not affect health. In this sense, our study is more similar to Dafny (2005) in that reimbursement distortions lead to higher public spending.

\footnotetext{
${ }^{14}$ In another related study, Brekke, Holmas, and Straume (2011) examine the effects of drug procurement policies in Norway on price competition between off-patent brand name and generic drugs. In a similar spirit to this paper, their empirical approach exploits quasi-experimental variation in the impact of a policy change across drug products to study the effects of reference pricing on prices and market shares.
} 


\subsection{Policy Significance}

Despite the perverse incentives of AWP-based reimbursement (and its potential for increasing drug spending), the AWP has been the dominant insurer reimbursement benchmark for over four decades, and it is still the primary benchmark for the majority of state Medicaid programs and many private insurers. As of the first quarter of 2013, 29 states still used the AWP as the benchmark price in setting Medicaid drug reimbursements, and 16 others used the WAC which is closely related to the AWP (CMS, 2013). The issue of AWP inflation has attracted considerable attention from government agencies and policymakers in recent years. While no policies have yet been put into place to fully replace the AWP, Medicaid has implemented several piecemeal interventions to mitigate AWP inflation, and it is possible that wholesale changes to the program will be implemented in the near future.

First, federal and state governments have introduced maximum limits on Medicaid reimbursement, known as FULs or MACs, for select generic and off-patent drugs. During the approximate midpoint of our study period, FULs covered over 200 drugs (OIG, 2001). ${ }^{15}$ For drugs subject to FULs, the reimbursement limit has been traditionally set as $150 \%$ of the lowest published price (e.g. AWP) within a group of equivalent drugs (KFF, 2002). ${ }^{16}$ However, under this rule, manufacturers still have an incentive to self-report higher prices to drive up the minimum price and, consequently, the FUL. Thus, these limits may not be effective at reducing reimbursement for covered drugs. In 2012, an audit by the Office of the Inspector General found that FULs based on published list prices were on average more than four times greater than actual acquisition costs (OIG, 2012).

Second, in 2005, the Deficit Reduction Act (DRA) legislated replacing the AWP with another payment benchmark called the Average Manufacturer Price (AMP). However, the provisions of the DRA were never implemented because pharmacy trade groups obtained a federal court injunction to prevent the publication and use of the AMP in reimbursement due to

\footnotetext{
15 Typically, multi-source drugs with three or more suppliers are eligible for FULs, however reports by the Office of the Inspector General (OIG, 2004a, 2004b) have found that many eligible drug groups do not receive FULs.

${ }^{16}$ The Affordable Care Act legislated a new benchmark for the FUL which was set to be $175 \%$ of the weighted average of the Average Manufacturer Price (AMP) as of October 2010. However, CMS has not yet implemented this new FUL benchmark, and as of August 2012 FULs were still based on published list prices such as the AWP (OIG, 2012).
} 
concern that this data-- which manufacturers currently report to Medicaid for use in its drug rebate program-- does not accurately reflect pharmacy prices (NASMD, 2010).

Third, state Medicaid programs, Medicare, and private insurers have recently filed a series of lawsuits alleging that drug manufacturers have reported inflated AWPs to pricing catalogues. In one example in 2010, three drug manufacturers Abbott Laboratories, Roxane Laboratories, and B. Braun Medical, faced a \$421 million settlement for having “engaged in a scheme to report false and inflated prices for numerous pharmaceutical products knowing that federal healthcare programs relied on those reported prices to set payment rates (DOJ, 2010).” The Department of Justice reports that over $\$ 2$ billion in settlements has been recovered to date by Medicaid and Medicare from drug manufacturers who have manipulated the AWP (DOJ, 2012).

Fourth, in another set of lawsuits, the publishers of pricing data themselves have been targeted for fraudulent practices. First Data Bank (a major supplier of AWP data to Medicaid) stopped publishing the AWP in September of 2011 as a result of a major lawsuit against the publisher (OIG, 2011). According to a report by the OIG (2011), the 45 states using the AWP as of early 2011 planned to respond to this change by 1) requesting AWP data from other publishers (10 states), 2) using the Wholesale Acquisition Cost (WAC) as the benchmark instead of the AWP (12 states), 3) collecting data on average acquisition costs (3 states), or 4) had no transition plan in place (20 states). ${ }^{17}$ The WAC, which has been the most popular alternative to the AWP, is also a manufacturer self-reported price and "in many instances it is currently the basis upon which the AWP is calculated (NASMD, 2010),” thus generating the same perverse reporting incentives and susceptibility for price inflation as the AWP.

Fifth, in a proposed rule issued by CMS in February 2012, which is currently set to become final in August 2013, the agency proposes to shift away from reimbursement based on “estimated acquisition cost” (EAC) to reimbursement based on “actual acquisition cost” (AAC). Under this new definition, states would be required to provide data to support that their reimbursement methodology is representative of AAC. The proposed rule as written does not explicitly state how the AAC is to be calculated, but it suggests that states could use "a national survey, to create a database of actual acquisition costs...state survey of retail pharmacy

\footnotetext{
${ }^{17}$ Three states intended to continue using the AWP but haven't selected an alternative publisher, 3 considered replacing the AWP with the WAC, 6 intended to discontinue the AWP but haven't taken steps to select a new benchmark, 8 had not decided whether they would continue AWP from another source or switch to WAC.
} 
providers... [or] alternatively, the use of an AMP " to determine reimbursement rates. ${ }^{18}$ Meanwhile, over the last two years, CMS has begun fielding a survey of retail pharmacies’ acquisition prices to compute a new national benchmark, known as the National Average Drug Acquisition Cost (NADAC). CMS says that it "expect[s] that states may consider the NADAC as a reference price when setting their reimbursement methodology,”19

The future of Medicaid drug reimbursement continues to be a highly contested policy issue. With future expansions in Medicaid enrollment under the Affordable Care Act, reducing excessive prescription drug spending is likely to become an even more critical issue in the near term. Even if and when the AWP is phased-out, alternative Medicaid reimbursement benchmarks such as the WAC, AMP NADAC, and others may generate similarly distortionary incentives as the AWP. Indeed, as is clear from the proposed CMS rule and resulting stakeholder comments, and from discussions of potential policy remedies (NASMD, 2010), designing feasible and sensible alternatives to these benchmarks is not straightforward. ${ }^{20}$ In this paper we estimate pharmacy and manufacturer responses to the AWP. Understanding the effects of AWP-based reimbursement on the pharmaceutical market is an important first step in evaluating policy alternatives that may generate similar perverse incentives. To the best of our knowledge, this issue has not been systematically explored previously.

\section{Intervention}

\subsection{Details of the DOJ Intervention}

This study focuses on a national investigation of AWPs by the DOJ and NAMFCU in the late 1990s. The agencies collected actual wholesale pricing data from wholesalers' catalogues which "revealed a pattern of misrepresentations by some drug manufacturers of the average wholesale prices and wholesale acquisition costs of certain of their products.” The actual

\footnotetext{
${ }^{18}$ The proposed rule is 42 CFR 447.518, as documented in: http://www.gpo.gov/fdsys/pkg/FR-2012-0202/html/2012-2014.htm, and listed as http://www.reginfo.gov/public/do/eAgendaViewRule?pubId=201210\&RIN=0938-AQ41, both accessed on 6/19/2013.

${ }^{19}$ For details on the NADAC see: http://www.medicaid.gov/Medicaid-CHIP-Program-Information/ByTopics/Benefits/Prescription-Drugs/Survey-of-Retail-Prices.html accessed on 6/19/2013.

${ }^{20}$ For example, the NADAC, which aims to measure acquisition prices more reliably than AWP, is derived from a voluntary survey of retail pharmacies. It therefore may not be representative of the universe of acquisition prices. Moreover, it excludes from its calculation discounts or rebates that are not listed on invoices. AMPs are prices charged by manufacturers, not paid by retail pharmacies, so they do not factor in wholesale markups.
} 
wholesale prices were substantially lower than published AWPs. In an effort "to ensure that Medicaid drug prices are based on true information,” NAMFCU sent a letter in February 2000 to all state Medicaid pharmacy directors notifying them of the misrepresentations. ${ }^{21}$ Beginning on May 1, 2000, First Data Bank provided states with revised AWPs based on the pricing data uncovered in this investigation for approximately 400 NDCs representing about 50 drug products. ${ }^{22}$ States were strongly encouraged by NAMFCU to use these revised AWPs in place of the published AWPs in calculating reimbursements for these drugs.

The 400 NDCs represent about 50 unique drugs and accounted for \$306 million of Medicaid spending in $1999 .{ }^{23}$ These drugs are all generic and off-patent injectable, infusion, and inhalation products, including about a dozen oncology drugs and blood clotting factors. The full list of drugs targeted by the DOJ is reported in Table A.1 in the Appendix. The extent to which the AWP had been inflated for these drugs is staggering. The interquartile range of published AWPs $^{24}$ relative to actual wholesale prices is 2.4 to 36.3 (for the median, the published AWP is 6 times the actual price). For example, in one case, a manufacturer had reported an AWP of $\$ 948.46$ for a pack of $2 \mathrm{ml}$ vials of the generic antibiotic Amikacin Sulfate, while the investigation found that the actual wholesale price was only $\$ 125.00$. Similarly large margins between the published AWP and the average wholesale price uncovered by the DOJ can be found for other drugs as shown in Table 1.

While all states received the recommendation to adopt the AWP revisions, the use of these new prices was voluntary. A survey conducted by the Office of the Inspector General (2001) found that as of January-March 2001, 30 states had incorporated some or all of the revised AWPs into their reimbursements to pharmacies. ${ }^{25}$ The remaining states continued to be supplied with the original, manufacturer-reported AWPs from First Data Bank. States that did not adopt the revisions expressed concern that the new prices were too low, potentially

\footnotetext{
${ }^{21}$ For example, see Office of the Attorney General, Medicaid Fraud Control Unit, State of New York, 2000.

${ }^{22}$ It was also indicated that First Data Bank would update the prices for the 400 NDCs from data from actual wholesale catalogs every 6 months. However, some states reported concern that First Data Bank would not update the prices unless the DOJ and NAMFCU continued to provide them with wholesale catalogue prices (OIG, 2001).

${ }^{23}$ This figure is calculated by the authors using Medicaid State Drug Utilization Data for all states except Arizona. Arizona is the only state that does not participate in the Medicaid Drug Rebate Program and therefore does not report drug utilization data to CMS.

${ }^{24}$ We compare the actual wholesale prices uncovered in the DOJ investigation (HHS, 2000) with the AWPs published in the 1999 Red Book.

${ }^{25}$ The states that adopted the revisions as of 2001 are: AK, CT, DC, DE, FL, HI, ID, IL, IN, KS, KY, MD, MN, MO, MT, ND, NH, NJ, NM, NV, NY, OK, OR, PA, SC, UT, VT, WA, WI, WV.
} 
compromising beneficiaries' access to these drugs (OIG, 2001). It is worth noting that states that had not adopted the revisions at the time of the survey may have decided to adopt them later or, in any case, adopted them in a de facto manner when catalogues stopped publishing the manufacturer-reported AWPs for targeted drugs in later years. ${ }^{26}$ Conversely, some early adopter states may have eventually discontinued the use of the AWP revisions. ${ }^{27}$

This intervention provides a “quasi-experiment” to study the impact of Medicaid procurement on price competition for generic drugs. It generated a large and sudden reduction in the price on which Medicaid reimbursement is based for a select set of NDCs within classes of bioequivalent products. Prices for the bioequivalent competitors of targeted NDCs were not directly affected by the DOJ intervention. That said, the competitors are not a set of pure “control” NDCs because although they were not singled out in the DOJ audit, the DOJ intervention may have changed the nature of AWP reporting itself. It is possible that after the DOJ announcement, drug manufacturers may have become more cautious in reporting highly inflated AWPs that might draw attention from regulators or litigators. To the extent that we see an effect on prescriptions and market shares for targeted drugs relative to competitor drugs, this should represent a downward biased estimate of the effect of the intervention. It should be noted that the intervention may also have led to changes in the actual acquisition price paid by pharmacies for the drugs. Unfortunately, we do not have acquisition price data and cannot investigate whether those prices changed in response to the intervention.

For the approximately 50 "treated” drug markets, we examine how the pharmacy market share for targeted NDCs changed following the reduction in the relative price of these drugs. We proxy for pharmacy market share using Medicaid utilization. ${ }^{28}$ Appendix Figure A.1 illustrates this “experiment” for one drug market, Acetylcysteine. In this market, only select NDCs of Acetylcysteine produced by the manufacturer Abbott were targeted by the DOJ (the large quantity packages), all Acetylcysteine NDCs produced by Faulding were targeted, and no

\footnotetext{
${ }^{26}$ For instance, the Red Book began to publish revised AWPs for some of the targeted NDCs in 2002.

${ }^{27}$ Finally, even among states that adopted the revisions, not all revised prices for targeted drugs were implemented. For example, some hemophilia groups claimed that treatment would be discontinued if prices were not increased, leading some states to exclude blood clotting factors from the revisions (OIG, 2001).

${ }^{28}$ Recall that the consumers should be price insensitive across bioequivalent generics produced by different manufacturers. Thus shifts in utilization from one manufacturer's version to another's version reflect changes in the purchasing patterns of pharmacies. Further, while Medicaid outpatient drug utilization corresponds one-to-one with pharmacy dispensing, our data will not capture changes in the total number of drugs purchased and stocked by pharmacies. We are unaware of any national-level dataset that would provide this level of detail on pharmacy purchasing.
} 
Acetylcysteine NDCs produced by Bedford were targeted. Since these targeted and nontargeted products are bioequivalent substitutes, we can test the effect of the differential price shock for targeted NDCs on their market share. As shown in the figure, the market share (as measured by prescriptions dispensed) of targeted Acetylcysteine NDCs plummeted after states adopted the DOJ prices.

Following the discussion in Section 2, we predict that the incentives embedded in Medicaid procurement rules should induce pharmacies to substitute away from the drugs that experienced the price reduction and towards their competitors' products, leading to a decline in the market share for targeted drugs. This contrasts with a standard model of price competition in which the price decline would be predicted to cause an increase in pharmacy market share. Consequently, if pharmacies reward higher-priced drugs with greater market share, this provides an incentive for manufacturers to compete by bidding up the published price.

\section{Data Sources}

\subsection{Data}

The main source of data for this paper is the Medicaid State Drug Utilization Data published by CMS. ${ }^{29}$ The data series tracks Medicaid spending and utilization by NDC for each state and quarter from 1991 through the present. NDCs only appear in the data if they have nonzero Medicaid utilization in the state and quarter. We aggregate the quarterly data to annual totals. ${ }^{30}$ We focus primarily on two variables: the number of prescriptions and the total reimbursement. From this we construct reimbursement per prescription and the market share for targeted drugs. Given that Medicaid reimbursement is largely determined by the AWP, reimbursement per prescription and AWP should be strongly correlated. The data set also includes information about NDC characteristics such as the drug name, FDA approval date, whether it is a generic or brand name drug, and the unit type (e.g. capsule, tablet, milliliter).

We obtained the list of 411 NDCs that were targeted by the DOJ from a Program Memorandum issued by the Department of Health and Human Services (HHS, 2000). ${ }^{31}$ This

\footnotetext{
${ }^{29}$ State Drug Utilization Data which is collected for the Medicaid Drug Rebate Program is available from the CMS website: https://www.cms.gov/MedicaidDrugRebateProgram/SDUD/list.asp

${ }^{30}$ The quarterly data are highly noisy. This variation may reflect when claims are processed rather than actual patterns in drug use.

${ }^{31}$ This memorandum was issued to notify the Medicare program of the alternative source of average wholesale data that was uncovered by the DOJ and NAMFCU for the Medicaid program.
} 
document contains the actual average wholesale price found in the DOJ audit for each NDC. We use the eleven-digit NDCs reported in this Memorandum to identify the targeted NDCs in the State Drug Utilization Data. We find that 379 of the 411 NDCs had non-zero Medicaid utilization the year before the intervention.

In this study, we compare changes in purchasing patterns for the targeted NDCs and their competitors whose prices were not directly revised by the DOJ. To identify a set of competitor drugs, we begin by identifying for each targeted NDC the set of drugs that share the same active ingredients as the targeted NDC. In choosing which drugs to stock and dispense, pharmacies may substitute between one generic and another (or a generic and an off-patent brand name drug) ${ }^{32}$ if they are bioequivalent. NDCs are bioequivalent if all of the following are true: the NDCs share the same active ingredient name, strength, and therapeutic equivalence rating as reported in the FDA publication, “Approved Drug Products with Therapeutic Equivalence Evaluations” (also known as the Orange Book).

Thus, the analysis sample includes the approximately 400 NDCs that received revised AWPs and all other NDCs (generics and off-patent brands) that have the same active ingredient names as those in the revised group. We use the drug name variable to extract these NDCs from the State Drug Utilization Data. ${ }^{33}$ For generic drugs, the drug name is the same as the active ingredient name. For off-patent brand name drugs (both active and discontinued), we use the Orange Book ${ }^{34}$ to obtain the list of brand names that have the same active ingredient name as the targeted NDCs. Using this market definition, there are 379 targeted NDCs and 2,839 competitor NDCs with positive Medicaid utilization in 1999. While this market definition is somewhat broader than generic bioequivalence, it allows us to capture possible substitutions across different formulations of a generic drug if pharmacists seek permission from the prescribing physicians to make these substitutions. ${ }^{35}$

\footnotetext{
${ }^{32}$ This sometimes requires permission from the prescribing doctor, but is at the discretion of the pharmacy in states with mandatory generic substitution laws.

${ }^{33}$ This process is aided by linking the utilization data by NDC code to CMS's Drug Product File in order to determine the full name of each drug product. In the full US sample, the Drug Product File can be linked to about $55 \%$ of the NDCs in the utilization data. For NDCs that are not matched with a full drug name, we use the abbreviated drug name that appears in the utilization data.

${ }^{34}$ The FDA Orange Book is available at http://www.accessdata.fda.gov/scripts/cder/ob/default.cfm

${ }^{35}$ For example, a pharmacy might respond to the DOJ intervention by stocking only the formulations of a generic drug which are most profitable (e.g. liquid version vs. tablet, or a specific concentration). Patients who receive a prescription for a formulation of a drug that is not stocked by the pharmacy may be induced by the pharmacy to switch to a different formulation with permission from their doctor.
} 


\subsection{Sample Restrictions}

We restrict our analysis to the period from 1994-2004, since changes in the composition of drugs over time make data further away from the intervention year less comparable. Our initial sample is constructed at the NDC-by-state-by-year level and includes 795,694 observations. We make three other sample restrictions. First, we exclude five states from the analysis: Arizona, Alabama, Ohio, Tennessee, and Texas. Arizona does not report drug utilization data to CMS because it does not participate in the Medicaid Drug Rebate Program. The other four states do not use AWP as their primary reimbursement methodology (OIG, 2001). This reduces the sample by 66,190 observations. Second, we drop NDCs for hemophilia drugs (Anti-Inhibitor Coagulant Complex, Factor VIII, Factor IX). Hemophilia patient groups opposed the DOJ recommended prices leading many states to implement alternative prices for these drugs (OIG, 2001). These three biological drugs are also unusually expensive relative to the other drugs targeted by the DOJ. They have the highest average reimbursement per prescription among drugs in the sample, ranging from $\$ 10,493$ to $\$ 16,369$ per prescription in $1999 .{ }^{36}$ Removing these drugs from the sample reduces total reimbursement by $15.59 \%$ and total prescriptions by only $0.04 \%$. Finally we exclude 5 observations that are extreme outliers in reimbursement per prescription, which are likely reporting errors. ${ }^{37}$

The final NDC-by-state-by-year sample includes 723,991 observations. Since the intervention occurred at the NDC level, we aggregate the data across states to form nationwide totals for each NDC (though later differentiate between states that adopted the DOJ prices early versus other states). There are 32,203 NDC-by-year observations in the final analysis sample.

\section{Empirical Evidence of Reverse Price Competition}

\subsection{Descriptive Statistics and Graphical Evidence}

We begin by presenting descriptive statistics and trends for reimbursement and prescriptions purchased. Much of the evidence for the intervention effect can be seen in the raw means and graphically. In Table 2, descriptive statistics are reported separately for NDCs that

\footnotetext{
${ }^{36}$ For comparison, Winrho SDF, which was the next most expensive drug in the sample, has a mean reimbursement per prescription of $\$ 2,080$ which is substantially lower than the cost of the hemophilia drugs.

${ }^{37}$ We remove the following outlier observations because they differ substantially from the same NDCs in other states and years: NDC=00074115170, ME, 1996; NDC=59075065220, WA, 2003; NDC=39769001101, IL, 1991; NDC=49669162301, AR, 2002; NDC=00026064920, VA, 1999.
} 
were targeted in the DOJ investigation and for their bioequivalent competitors. Means of variables are presented for units aggregated at the NDC level, except for the drug group market share variable, which is aggregated at the "drug group" level (i.e. the class of drugs that share the same drug name). The means are shown for 1999 and the change between 1999 and 2002. Columns 1 and 2 reveal that the DOJ-targeted NDCs were on average about 3 times more expensive than their bioequivalent competitor NDCs in 1999. The targeted NDCs were also Medicaid market leaders with an average market share that was more than 5 times as large as their competitors' market shares. However, since there were fewer targeted NDCs, they made up a smaller share of the overall market. Targeted drugs were also much more likely to have a liquid formulation than competitor drugs, which may explain some of the price differential.

We first show suggestive evidence that pharmacies may have shifted away from purchasing targeted drugs following the intervention. The data show a decline in both mean Medicaid reimbursement per prescription and the number of prescriptions dispensed for targeted NDCs from 1999 to 2002, coinciding with the timing of the DOJ intervention. In the same time period, reimbursements per prescription and sales increased for competitor NDCs.

We further examine whether the 1999-2002 change in reimbursement and prescriptions varied across competitor drugs depending on whether or not their manufacturer was targeted by the DOJ for other NDCs within the same drug class. We might expect that competitor NDCs produced by targeted manufacturers would respond differently to the intervention for a few reasons. First, because these manufacturers were under increased scrutiny by the DOJ, they may have halted price growth or even lowered prices on non-targeted products in attempt to avoid further investigation. Second, targeted manufacturers may have been able to more readily switch marketing and production efforts between their targeted and non-targeted products within a drug group, leading to a large observed increase in non-targeted "competitor" products. On the other hand, this effect would be mitigated if pharmacies were reluctant to purchase non-targeted products from the manufacturers who were under the most scrutiny.

Columns 3 and 4 report means for competitor NDCs produced by targeted and nontargeted manufacturers. Competitor NDCs produced by targeted firms are very similar to targeted NDCs (Column 1) in terms of observable characteristics, such as baseline reimbursement per prescription and unit type. Moreover, similar to targeted NDCs, competitor NDCs of targeted firms saw a small decline in their average reimbursement following the 
intervention. In contrast, reimbursement per prescription increased by 25 percent for competitor NDCs of non-targeted firms. NDCs from non-targeted firms also experienced substantially larger growth in the average number of prescriptions purchased relative to competitor NDCs from targeted firms (a 56\% versus $0.5 \%$ increase). While the means presented in this table are consistent with the hypothesized effects of the DOJ intervention, the changes in outcomes from 1999-2002 may also reflect differences in longer-term trends across targeted and competitor NDCs.

Figure 1 documents how reimbursement per prescription, prescription purchases, and market share evolved from 1991 through 2004 for targeted and competitor NDCs. Prior to the intervention, mean reimbursement per prescription had been rising rapidly since 1991 for both sets of drugs. For targeted drugs, reimbursement per prescription flattened and then declined sharply after the intervention in 2000. The leveling off before 2000 may reflect an early response to the intervention, given that the DOJ's planned policy was outlined to Medicaid State Pharmacy Directors at a national conference in the summer of $1999 .{ }^{38}$ The drop in reimbursement per prescription was not a one-time change, but continued to decline until 2003. This is not surprising given the gradual adoption of the DOJ recommendations by many states. In contrast, there was no corresponding break in the reimbursement trend for the competitor NDCs with average reimbursement continuing to increase through 2004. These two graphs suggest that the DOJ recommendations had a real impact on actual Medicaid reimbursement trends-- reducing the price of targeted drugs relative to competitors' prices.

In panel B, trends for the quantity of prescriptions purchased mimic the reimbursement trends. For targeted and competitor NDCs there are trend reversals following the intervention: prescriptions declined for targeted NDCs and increased for competitor NDCs. Moreover, the overall market share of targeted drugs declined after the intervention (Panel C). This is strong suggestive evidence of a substitution effect. For competitor NDCs, the reversal in trend for prescriptions (and targeted market share) occurred one year prior to the intervention. We examine this further in Figure 2 by separately plotting the trends in average annual prescriptions per NDC for competitor NDCs manufactured by targeted firms and non-targeted firms. Both trends increased throughout the study period. Nonetheless, the figure also shows a noticeable uptick in prescriptions in 1999 for competitor NDCs manufactured by targeted firms. One

${ }^{38}$ Office of the Attorney General, Medicaid Fraud Control Unit, State of New York, 2000. 
possible explanation for this sudden jump in prescriptions is that targeted firms may have anticipated the intervention and tried to circumvent a loss in market share by shifting sales to non-targeted products within each drug group. If this uptick represents an anticipatory response by targeted firms, then measuring the change in prescriptions using 1999 as the base year (as in Table 2) attenuates the effect of the intervention for competitor drugs.

\subsection{Main Regression Results}

\subsubsection{Reimbursement per Prescription}

To estimate the magnitude of the changes in reimbursement per prescription and prescriptions purchased, we turn to regression analysis. We begin by documenting the impact of the DOJ intervention on average reimbursement per prescription. If DOJ prices are incorporated into state reimbursement policies, we would expect to observe a reduction in the actual Medicaid reimbursement paid per prescription for the targeted NDCs starting in 2000. The differential impact of the intervention on reimbursement per prescription for targeted NDCs relative to competitor NDCs is a necessary criteria for identifying the impact of price on pharmacy purchasing decisions.

We first estimate a non-parametric model to test whether there is a structural break in the targeted NDC trend relative to the competitor NDC trend around the time of the intervention in 2000:

$$
\log \left(Y_{j t}\right)=\gamma_{t}+\mu_{j}+\beta_{t} * \text { Target }_{j}+\epsilon_{j t}
$$

The dependent variable is the $\log$ of reimbursement per prescription for $N D C_{j}$ in year $t$. We estimate proportional changes in reimbursement per prescription to allow for comparisons across drugs with widely different initial reimbursement levels. We control for permanent differences across NDCs and common year effects with a vector of NDC fixed effects $(\mu)$ and a vector of year fixed effects $(\gamma)$, respectively. Target $_{j}$ is an indicator variable which equals one for targeted NDCs and zero for competitor NDCs. Standard errors are clustered at the drug group level $^{39}$ to allow for correlation across NDCs within drug groups and serial correlation over time.

\footnotetext{
${ }^{39}$ The drug group is the group of NDCs that share the same drug name.
} 
The main coefficients of interest are the vector of estimated $\beta$ 's, in which each $\beta_{t}$ gives the change in the targeted-competitor reimbursement difference between year $t$ and the (omitted) reference year of 1999. These coefficients are reported in Column 1 of Table 3. Targeted and competitor NDCs appear to have had the same reimbursement trends before the intervention, as reflected in the statistically insignificant coefficients prior to 2000. However, after states adopted DOJ prices in 2000, there was a very large and statistically significant relative decline in reimbursement per prescription for targeted drugs. This differential continued to widen until 2003 and then leveled off. Between 2000 and 2004, the relative reimbursement per prescription fell by 26\% for targeted drugs compared to the 4 year change between 1994 and 1998 $\left(\exp \left(\left[\beta_{04}-\beta_{00}\right]-\left[\beta_{98}-\beta_{94}\right]\right)-1\right)$.

Based on the results from the non-parametric model, we next parameterize this specification by imposing a trend break in 2000 and allowing the effect to have a level and slope shift. This model allows us to estimate an average intervention effect. We also allow targeted and competitor NDCs to have separate linear trends. The slope shift is motivated by the graphical evidence in Figure 1 which showed that the drop in the reimbursement per prescription was not a one-time change but continued to decline over time as more states adopted the DOJ recommendations. The estimating equation is:

(3) $\log \left(\mathrm{Y}_{\mathrm{jt}}\right)=\gamma_{t}+\mu_{j}+\alpha_{1}$ Target $_{j} \cdot$ Post $_{t}+\alpha_{2}$ Target $_{j} \cdot t+\alpha_{3}$ Target $_{j} \cdot$ Post $_{t} \cdot(t-2000)+\epsilon_{j t}$

Post $_{t}$ is an indicator that equals 1 in 2000-2004 and zero in 1994-1999. $t$ is a linear time trend and $(t-2000)$ equals 1 in 2001, 2 in 2002 and so forth. Standard errors are again clustered at the drug group level. The intercept shift for targeted NDCs relative to competitor NDCs is measured by $\alpha_{1}$ and the differential slope shift by $\alpha_{3}$. The key identifying assumption is that reimbursement per prescription for targeted and competitor NDCs would have continued along the same trends in the absence of the intervention. Combining these coefficients as $\alpha_{1}+4 * \alpha_{3}$ gives the estimated effect of the intervention on targeted NDCs through 2004. The results from estimating Equation 3 are reported in Column 2 of Table 3. There is a statistically significant differential intercept and slope shift for targeted NDCs after 2000. The intervention appears to have reduced average reimbursement per prescription by 44\% through 2004 
$\left(\exp \left(\alpha_{1}+4 * \alpha_{3}\right)-1\right)$. This estimate is larger than the non-parametric estimate because the point-by-point comparison did not account for an intercept shift. ${ }^{40}$

In column 3, we examine the robustness of this result to adding linear trends that vary by drug group $\delta \mathrm{x}$ Target cells. Given the limited statistical power, we do not use NDC-specific time trends in this analysis -- which would be the most flexible specification. We continue to constrain the slope and intercept shifts to be the same for all targeted NDCs and for all competitor NDCs. This model, which adds flexible time trends to Equation 3, is estimated as follows:

$$
\begin{aligned}
& \quad \log \left(\mathrm{Y}_{\mathrm{jt}}\right)=\gamma_{t}+\mu_{j}+\text { Target }_{j} \cdot \delta_{g} \cdot t+\omega_{1} \text { Target }_{j} \cdot \text { Post }_{t} \\
& +\omega_{2} \text { Target }_{j} \cdot \text { Post }_{t} \cdot(t-2000)+\epsilon_{j t}
\end{aligned}
$$

The results are highly robust to the more flexible specification. The results suggest that reimbursement per prescription declined by 50\% through 2004 for targeted NDCs relative to competitor NDCs $\left(\exp \left(\omega_{1}+4 * \omega_{2}\right)-1\right)$. Next, as a sensitivity test, we exclude competitor NDCs whose manufacturers were targeted by the DOJ for other NDCs within the same drug group -- thus comparing targeted NDCs with competitor NDCs whose firms were not targeted for other drug products. As discussed earlier, competitor NDCs made by targeted manufacturers may respond differently to the intervention given the likelihood that they are under heightened scrutiny and also because they can shift market share between their targeted drugs and their own non-targeted bioequivalent products. The results in Column 4 show that the intercept shift and slope shift are slightly larger after excluding these NDCs. The total effect of the intervention on reimbursement per prescription through 2004 is 54\% for targeted NDCs, which is only slightly larger than the previous estimate using the full sample.

It should be noted that the results presented in this section likely represent lower bound estimates of the DOJ's impact on reimbursement per prescription for two reasons. First, the estimates represent aggregate effects. Since not every state adopted DOJ prices or implemented the full set of recommended changes, the aggregate effect is smaller than the impact on states that were fully compliant with DOJ recommendations. Second, we can only observe prices for drug products with positive sales. If the products with the largest price declines were more likely

\footnotetext{
${ }^{40}$ Estimating the intervention effect using only a slope shift results in a $25 \%$ decline $\left(\exp \left(4 * \alpha_{a}\right)-1\right)$ in reimbursement per prescription which is very close to the estimate of $26 \%$ from the non-parametric model.
} 
to be discontinued by manufacturers or generate zero sales, our estimate would understate the impact of the intervention on reimbursement per prescription since the largest price reductions are selected out of the sample.

\subsubsection{Prescriptions Purchased}

Given the substantial differential impact of the DOJ intervention on reimbursement per prescription for targeted NDCs, we next examine how pharmacy purchasing decisions responded to this plausibly exogenous price shock. There are three main mechanisms through which the intervention could have caused changes in the quantity and composition of generic drugs used by Medicaid beneficiaries. First, pharmacies may have reduced their purchasing of targeted NDCs (whose relative price declined) and substituted towards competitor NDCs (whose relative price increased)--thereby lowering the pharmacy market share of targeted drugs. Second, reductions in reimbursement may have reduced access to these drugs for Medicaid beneficiaries. For example, manufacturers may respond to reduced demand for their products following the DOJ intervention by discontinuing production of targeted generic drugs. Consolidation in the number of generic producers for a given drug may make these products vulnerable to shortages which reduce access

to beneficiaries (Chabner, 2011; Yurukoglu, 2012). The reduced reimbursement may also affect pharmacies’ decisions to stock and dispense drugs for Medicaid beneficiaries-- a noted concern by patient groups, which may have prevented some states from adopting DOJ prices (OIG, 2001). This would cause a decline in the total prescriptions dispensed for these drug groups.

Finally, manufacturers may have strategically discontinued products that were targeted by the DOJ and re-introduced these products (repackaging the drug or modifying the formulation with a new NDC). If manufacturers introduce a new version of a targeted drug, the product will be assigned a new NDC code which will not be subject to the price recommendations made by the DOJ. Thus, manufacturers can circumvent profit loss by discontinuing targeted NDCs and introducing new, modified versions of these products that would not be targeted by the policy. If this type of product exit and entry occurred, we would observe a decline in targeted market share.

In this analysis, we do not attempt to separately identify the relative contribution of each of these mechanisms to the change in prescription quantities. Instead, we use measures that summarize the total intervention effect: market share of targeted drugs and total prescriptions 
purchased in the drug group. In order to capture changes to market share that occur through the introduction or discontinuation of NDCs, we aggregate the data to drug group-by-year cells. Again we begin by estimating year effects in a non-parametric model in order to identify trend breaks in the time series:

\section{(5) MKTSHARE $_{\mathrm{gt}}^{\mathrm{T}}=\varphi_{g}+\gamma_{\mathrm{t}}+\epsilon_{g \mathrm{t}}$}

The dependent variable is the market share for targeted drugs, computed as the number of prescriptions of targeted NDCs in drug group $g$ in year $t$ divided by the total number of prescriptions in drug group $g$ in year $t$. Observations with zero targeted market share are included. However we exclude any drug group-by-year observations for years in which there are no sales for both targeted and competitor NDCs in the drug group. This leaves 480 drug groupby-year observations. We control for drug group fixed effects $(\varphi)$ and include a set of year fixed effects $(\gamma)$, treating 1999 as the reference (omitted) year. We cluster standard errors at the drug group level.

Column 1 of Table 4 reports the full set of $\gamma_{t}$ coefficients which trace out the time pattern of market share for targeted drugs from 1994-2004 relative to market share in 1999. The negative coefficients before and after the reference year reflect an increasing trend in targeted market share during the pre-period and a decreasing trend following the intervention. Although the change between 1999 and 2000 is not statistically significant, the negative coefficients in 1998 and 2000 suggest that the trend reversal may have begun in 2000 as predicted. The decline in targeted market share accelerated through 2004. A joint significance test rejects that all of the negative coefficients following the intervention are equal to zero at the $10 \%$ level. Relative to the 4-year change from 1994 to 1998, the intervention led to a statistically significant decline in targeted market share of 16.1 percentage points from 2000 and 2004 ( $\left[\gamma_{04}-\gamma_{00}\right]-\left[\gamma_{98}-\gamma_{94}\right]=-0.161$ with a standard error of 0.058$)$. This suggests that pharmacies substituted towards the competitor products after the intervention.

Next, we parameterize the effect by estimating a linear trend break model which is analogous to Equation 3:

(6) MKTSHARE $_{\mathrm{gt}}^{\mathrm{T}}=\alpha_{1}$ Post $_{t}+\alpha_{2} t+\alpha_{3}$ Post $_{t} \cdot(t-2000)+\mu_{g}+\epsilon_{g t}$ 
The results in Column 2 of Table 4 show that there was a statistically significant slope change in the trend for targeted market share in 2000 and a statistically insignificant intercept shift. The market share for targeted drugs fell by 18.4 percentage points by $2004\left(\alpha_{1}+4 * \alpha_{3}\right)$, a $45 \%$ decline relative to the baseline mean of $40.9 \%$ in 1999 . This is similar to the effect size found in the non-parametric specification when one considers the pre-existing trend in the average targeted market share. In Column 3 of Table 4, we add drug group specific linear time trends. The more flexible specification produces slightly larger effects suggesting that targeted market share declined by an average of 18.8 percentage points by 2004 (a 46\% reduction). ${ }^{41}$

In Columns 4 and 5, we decompose the change in competitor drugs' market share by whether or not the NDCs were manufactured by targeted firms. We re-estimate the most flexible version of Equation 5 using competitor market shares for targeted firms or non-targeted firms as the dependent variables. Consistent with the descriptive statistics and visual evidence discussed earlier, there was a smaller increase in market share for competitor drugs manufactured by targeted firms (3.0 percentage point increase through 2004 versus 15.9 percentage points). This may reflect pharmacies reluctance to substitute towards competitor NDCs from the firms that have a higher chance of being targeted in future DOJ investigations.

\subsection{Additional Specifications}

\subsubsection{Effects for Early Adopter States versus Other States}

As discussed in Section 3.1, not all states adopted the DOJ recommendations immediately. Some states may have adopted the recommendations with a lag or not at all. In Table 5, we compare the time pattern of reimbursement per prescription and targeted market share for the 30 states that reported in an OIG survey (2001) that they had incorporated some or all of the recommended AWP changes as of January-March 2001 (Columns 1 and 3) with all

\footnotetext{
${ }^{41}$ A reasonable next step is to combine the estimate of the effect of the DOJ intervention on price (Column 3 of Table 3) with the effect on market share (Column 3 of Table 4) to compute an indirect least squares estimate of the price elasticity of pharmacy demand. This estimate is $0.92(0.46 / 0.50)$, a positive number that is at odds with that of a standard competitive market in which the lowest priced drugs capture the highest pharmacy market share.

However, this is suggestive since we do not have enough statistical power to precisely estimate this price elasticity.
} 
other states (Columns 2 and 4). ${ }^{42}$ We would expect to find a differential effect for the early adopter states in the early years after the recommendations were released.

As shown in Columns 1 and 2, the differential decline in reimbursement for targeted NDCs was much larger for early adopter states during the first few years after the intervention. Over time, the decline for the two groups of states converged, as more states adopted the recommendations. This pattern of the timing of the response across states provides more reassuring evidence of a causal relationship between the DOJ policy and the observed decline in price.

In Columns 3 and 4, we also compare trends in targeted market share for early adopter states and all other states. Consistent with the time patterns for reimbursement per prescription, targeted market share declined earlier and was greater in magnitude for early adopter states. For the states that hadn't adopted the revisions at the time of the survey in 2001, market share did not begin to decline until 2003. This mimics the results for reimbursement per prescription, which showed that reimbursement for targeted NDCs declined primarily in the later years of the postintervention period for the states that hadn't initially adopted the revisions.

\subsubsection{Treatment Heterogeneity by Market Characteristics}

We next examine heterogeneity in the effects on reimbursement and prescriptions purchased across the approximately 50 drug markets affected by the DOJ intervention. Significant variation exists across markets with respect to the initial market share of targeted drugs, the magnitude of the pre-intervention spread for targeted drugs, and the number of firms producing competing drug products. In Table 6, we test for heterogeneous effects in log reimbursement per prescription (Panel A) and targeted market share (Panel B) by interacting the intercept and slope terms in Equations 4 and 6 with indicators for these market characteristics.

For each of the market characteristics that we consider and for both dependent variables we run two separate regressions - one for the full sample, and one for a trimmed sample where

\footnotetext{
${ }^{42}$ As in our previous specifications, we exclude Arizona which does not provide drug utilization data to Medicaid and the four states (AL, OH, TN, TX) that the OIG survey (2001) identified as relying on "methods other than the AWP as its primary reimbursement methodology.” While these four states might appear to provide a natural "control" group with which to test the effects of the DOJ policy on the other states, these states also may have incorporated some or all the DOJ prices into their own reimbursement methodologies. For example, there is documentation suggesting that Texas adopted the DOJ prices in 2000 for the targeted drug products (Texas Office of the Comptroller, 2003). Because of the uncertainty surrounding the reimbursement policies in these four states, we exclude them from the analysis.
} 
we exclude drug groups with targeted market share below 5\%, and four drug groups with targeted market share greater than 95\% (three out of the four are 100\%). We report results for the trimmed sample because the responsiveness of these drugs groups to the DOJ intervention is muted because they are bounded from below or above. ${ }^{43}$ Full sample results are reported in even numbered columns and trimmed sample results are in odd numbered columns.

We begin by repeating the baseline specification results in Column 1 for the full sample, and then reporting the results for the trimmed sample in column 2. The baseline results are largely robust to excluding drug groups with the most limited scope for a market share response. We then report results showing how the treatment effects differ across drug groups with initial targeted market share above or below the median. In the full sample, for drug groups classified as above the median, targeted drugs accounted for on average $71 \%$ of the market prior to the intervention, compared to $10 \%$ for drug groups classified as below the median. In Columns 3 and 4, we report coefficients for the main slope and intercept terms and the interaction of the main effects with an indicator for whether the drug group’s initial targeted market share was above the median. As shown in Panel A of Table 6, drug groups with high or low initial targeted market share experienced similar proportional reductions in reimbursement per prescription following the intervention. However, as shown in Panel B, the decline in market share is almost entirely concentrated among drug groups where targeted drugs initially comprised a larger share of the market. The coefficient on the slope term interacted with the above median initial targeted market share is -0.084 and is statistically significant at the $1 \%$ level (implying a $58 \%$ decline in targeted market share through 2004 for drug groups above the median), while the main effects, capturing the responses for below median drug groups, are close to zero and statistically insignificant. These results can be largely explained by the fact that markets with low initial targeted market share simply have less scope for decreasing market share.

In Columns 5 and 6, we test for heterogeneity across drug groups which had smaller or larger spreads. We use the published AWP in the 1999 Red Book and the actual acquisition price uncovered in the DOJ audit to compute actual spreads for each of the targeted NDCs in the baseline year. To obtain a prescription-weighted average spread for each drug group, we simulate total reimbursement for all NDCs in the drug group under the AWP benchmark (i.e.

\footnotetext{
${ }^{43}$ Trimming the sample to exclude drug groups with targeted market share less than $1 \%-4 \%$ and greater than or equal to $96 \%-100 \%$ produce very similar results. Results are available upon request.
} 
summing the product of the AWP and number of prescriptions across NDCs) and divide that by simulated total reimbursement using the actual acquisition price as the benchmark. Then we interact the slope and intercept terms with an indicator for whether the drug group had an average spread that was larger than the median (AWP is 3.4 times as large as the acquisition price). As expected, in both Columns 5 and 6, we find that reductions in reimbursement per prescription are much greater for drug groups with the largest spreads at baseline. In response to the differential decline in reimbursement, we find that targeted market share also declined more for the drug groups with a larger initial spread. The difference between the two subgroups is not statistically significant in the full sample, but is larger in absolute value and statistically significant in the trimmed sample. The insignificance of the difference in the full sample appears to be largely due to a set of low targeted market share drug groups that have limited scope for downward adjustment. Over a four year period, the difference, as reported in the trimmed sample in Column 6, amounts to a relative decline of 28 percentage points.

Finally, in the last two columns of Table 6. we compare the treatment effects for drug markets that are more or less concentrated. We identify the number of manufacturers producing products in each drug group by counting the number of unique labeler codes, the first 5-digits of the NDC, in 1999. Drugs produced by an above median number of manufacturers have on average 24 competing firms, whereas below median drug groups have on average 3 competing firms. For both the full and trimmed samples, the number of manufacturers producing a drug does not strongly predict a differential response for reimbursement per prescription. Similarly, we do not find a statistically significant differential effect of market concentration on targeted market share.

\subsection{Additional Margins of Adjustment}

Thus far we have focused on the substitution effect of the intervention: pharmacies switching between targeted and competitor drugs. It is worth noting that the inflated AWP prices of Medicaid prescriptions for targeted drugs prior to the intervention, plus the distortion of Medicaid prescriptions toward these drugs, implies negative effects on welfare. Tax revenue must be higher to fund Medicaid reimbursement of these prescriptions at inflated prices, which results in higher deadweight loss. This suggests that the DOJ intervention increased welfare, rather than just having served as a neutral transfer from pharmacies to the government. Of 
course, there also are other important margins over which the intervention may have led to changes in behavior for manufacturers, pharmacies, payers, and consumers, any of which could have affected overall welfare. A full welfare analysis would require consideration of all of these margins, which goes beyond the scope of this paper (and, in some cases, beyond the scope of available data), but represents a potentially fruitful area for future research. Nonetheless, the fact that we do find large distortions in behavior resulting from inflated AWP pricing does suggest that there likely were substantial negative effects on welfare. Here we provide preliminary evidence on the effects of the intervention on three other important margins of adjustment by manufacturers and pharmacies_-access, total spending, and the introduction and discontinuation of NDCs.

\subsubsection{Impacts on Access to Prescription Drugs by Medicaid Beneficiaries}

The decline in reimbursement may have reduced access to the targeted drug groups for Medicaid beneficiaries. For example, pharmacies may have responded to the reduced profit margins for generic drugs by choosing not to dispense certain targeted drugs to Medicaid beneficiaries and manufacturers may have discontinued producing some targeted drugs, reducing the availability of treatments overall.

In Table 7, we provide a preliminary test for these extensive margin effects. In Column 1, we estimate Equation 6 using the log of total prescriptions (i.e. the number of prescriptions for targeted plus competitor NDCs) in drug group $g$ in year $t$ as the dependent variable. This

provides suggestive evidence for whether the intervention reduced Medicaid beneficiaries' access to DOJ-targeted drug groups. The point estimates of the slope and intercept shift suggests that the quantity of total prescriptions did fall by a small amount, but the standard errors are large and we cannot conclude that there was a trend break in access to targeted drug groups for Medicaid beneficiaries after the intervention. This is consistent with the graphical evidence presented in Appendix Figure A.2 (Panel A) which also does not show a clear trend break in total prescriptions.

\subsubsection{Strategic Product Introduction and Discontinuation}

Next, we consider another supply-side mechanism through which we may observe substitution between targeted and competitor drugs following the intervention. Manufacturers of 
targeted NDCs may have strategically responded to the DOJ targeting by introducing and marketing new products with new NDC codes that are close substitutes of their targeted NDCs. For example, one way that manufacturers could strategically respond to the intervention is by reintroducing targeted products with new package sizes. Since the last two digits of the NDC code determine the package size, these new products will be assigned new NDCs and would not be subject to DOJ pricing recommendations. Manufacturers could then set new AWPs for these NDCs in any way they desire. For the purposes of this analysis, such new products are classified as “competitor NDCs.”

Introducing new products is costly for manufacturers as it requires obtaining necessary FDA approvals, shifting production resources, and marketing to generate pharmacy market share for the newly re-packaged or re-formulated products. Even if new products are bioequivalent to the targeted versions and there is no impact on the overall availability of drugs for Medicaid beneficiaries, proliferation of these newly introduced substitute NDCs may have welfare implications. If the prices of the new products are greater than the DOJ-recommended prices of their targeted counterparts, the strategic introduction of NDCs undoes some of the potential costsavings to the Medicaid program of the policy change and, at the same time, leads to higher profit margins for pharmacies and/or manufacturers (and presumably increased deadweight loss from increased taxes to fund higher Medicaid reimbursements). Thus, the overall welfare implications arising from a reimbursement policy that leads to strategic product substitution are likely to be negative.

In Table 8, we report the results from specifications that examine whether there were strategic entry and exit decisions caused by the DOJ policy. We note at the outset that our empirical "test” is simplistic; a more formal analysis would require simultaneous modeling of product entry and exit decisions, consideration of product differentiation at the drug class level, and other considerations typical of comprehensive industry studies. Therefore, we consider these findings suggestive but not definitive.

If manufacturers of targeted NDCs strategically introduced new NDCs to replace their targeted NDCs, we would observe an uptick in the fraction of new competitor NDCs produced by targeted firms in drug groups that had a targeted NDC relative to the fraction of new competitor NDCs produced by non-targeted firms. ${ }^{44}$ To examine whether this occurred, we first

\footnotetext{
${ }^{44}$ This assumes non-targeted firms' incentives to introduce new NDCs were not affected by the DOJ intervention.
} 
calculate for each drug group the stock of competitor NDCs with positive sales that were produced by targeted firms and non-targeted firms in an early base year, 1995, well before the DOJ intervention, and in a later base year, 1999, right before the DOJ intervention. We then calculate the ratio of the number of new NDC entrants in each drug group ${ }^{45}$ over the subsequent three years (1996-1998 or 2000-2002) divided by the stock of NDCs in the corresponding base period. ${ }^{46}$ We then average these rates of entry in each time period across drug groups for targeted and non-targeted firms separately.

As shown in the first row of Panel A in Table 8, there was an average $47 \%$ increase in the total number of NDCs produced by targeted firms in the early time period (between 1996 and 1998) due to entry. The rate of introduction fell to $12 \%$ for the time period between 2000 and 2002 (relative to the stock in 1999) following the DOJ policy. This decrease may have arisen for many reasons, including natural product life cycles that had nothing to do with the DOJ policy. Because of that, in the second row of Panel A, we similarly compute the change in the rate of NDC introduction for non-targeted firms, in order to construct a basic difference-in-difference estimate of strategic product entry decisions by targeted firms relative to non-targeted firms. As shown in the second row, non-targeted firms also slowed their rate of new product entry in these drug groups and by an even greater amount, from $86 \%$ to $29 \%$. The difference-in-difference estimate of 22 percentage points suggests that the rate of introduction increased after the intervention for targeted firms relative to non-targeted firms, but it is not statistically significant. ${ }^{47}$ Moreover, the fact that the rates of new product introduction were so different for targeted versus competitor firms before the DOJ policy may suggest the potential for differential trends, which we have not accounted for here. Nonetheless, we find the large point estimate of strategic entry suggestive enough to warrant future research. With respect to policy design, it is critical to understand whether a Medicaid policy that targets specific drug products to constrain costs causes other distortions to unregulated drug products (i.e. proliferation of new unregulated

\footnotetext{
${ }^{45}$ An NDC is considered an entrant in the first year that they are observed with positive Medicaid sales.

${ }^{46}$ We use the number of NDCs in the two base periods as the denominators, rather than the total number of NDCs during the two three-year periods we examine in order to abstract from product exits that could have occurred simultaneous to introductions.

${ }^{47}$ Measured in proportional terms the declines were similar and actually slightly larger for targeted firms (74 percent versus 67 percent). Indeed, given the baseline entry rate for targeted firms of 47.3 percent, it would not have been possible for their entry rates to decline by 56.9 percentage points as they did for competitor firms.
} 
versions of targeted products) in order to mitigate the costs of these constraints (see also Duggan and Scott-Morton, 2006). ${ }^{48}$

In Panel B of Table 8, we report results from a similar analysis for product exit during the periods pre- and post-DOJ policy. The first row of panel B reports that, on average, 7 percent of competitor NDCs produced by targeted firms exited prior to the DOJ policy, and that the rate of exit increased appreciably, to 17 percent after the policy. The second row of Panel B reports that the rate of exit for products produced by competitor firms also increased between the cohorts, from 23 percent to 38 percent. The difference-in-difference estimate suggests that the change in the rate of exit was 6 percentage points lower for targeted firms than competitor firms, though this result is not statistically significant. The point estimates are consistent with the possibility that firms that produced targeted NDCs may have chosen to keep other competitor products in the same drug class on the market longer than they would have otherwise, substituting marketing and production efforts away from their DOJ-targeted products. ${ }^{49}$

While the results of strategic introduction and discontinuation by targeted firms as a result of the DOJ policy are not conclusive statistically, we find the point estimates suggestive enough to warrant more investigation in future research.

\subsubsection{Effects on Total Medicaid Spending}

Finally, we consider preliminary evidence of the net effect of drug product substitution, introduction, and discontinuation on total Medicaid reimbursement following the DOJ intervention. In Table 7 (Column 2), we estimate an interrupted time series specification as in Equation 6. The dependent variable is the log of total reimbursement (i.e. the total reimbursement for targeted and competitor NDCs) in drug group $g$ in year $t$ and we include indicators for intercept and slope shifts, drug group fixed effects, and drug group-specific linear trends. While we cannot rule out other shocks to reimbursement during this time period, there was a statistically significant break in the reimbursement trend after the intervention, which is also apparent graphically in Appendix Figure A.2 (Panel B). If this entire change was due to the adoption of new DOJ prices, then the intervention would have generated on average a $40 \%$

\footnotetext{
${ }^{48}$ This response is known as "multi-tasking" in other contexts (Holmstrom and Milgrom, 1991) and is likely to be an issue for any targeted approach to cost containment.

${ }^{49}$ Targeted firms may have discontinued targeted drugs more frequently or more rapidly than otherwise also as a result of the policy. By definition, no targeted drugs were discontinued prior to 2000, but between 2000 and 2002, 6 percent were discontinued.
} 
$\left(\exp \left(\alpha_{1}+4 * \alpha_{3}\right)-1\right)$ reduction in total Medicaid reimbursement for the drug groups affected by the policy. This effect combines: 1) the mechanical effect of a reduction in reimbursement for targeted drugs with 2) substitution towards competitor drugs whose absolute prices were on average less than the initial prices paid for targeted drugs even after their prices increased.

\section{Conclusion}

Current Medicaid procurement rules generate perverse incentives for pharmacies to purchase and stock the highest-priced generic drugs. Consequently, manufacturers of generic drugs may compete for pharmacy market share by perversely bidding up the price on which Medicaid reimbursement is based. The DOJ recommendations to reduce the AWP for approximately 400 drug products provides an opportunity to study the impact of Medicaid procurement on generic drug price competition.

We find that Medicaid reimbursement per prescription declined substantially for targeted drugs following the DOJ intervention. In response to this negative price shock, pharmacies reduced their demand for targeted drugs and increased their demand for competitor drugs. Overall, the Medicaid market share for targeted drugs fell by about 45\% through 2004 . We also observe a differential decline in price and market share across states, which is consistent with the time pattern of adoption of the DOJ recommendations. Further, we find larger market share responses for drug groups in which targeted drugs had higher spreads and larger market share in the pre-intervention period as predicted. Taken together this evidence suggests that pharmacies substitute away from low priced generic drugs towards high priced drugs when making purchasing decisions. This demand response, while consistent with profit-maximizing behavior, is inconsistent with a typical competitive market in which the lowest-priced drugs capture the highest market share. This distortion has significant consequences for pharmaceutical spending.

Finally, we also examine whether the policy-induced reduction in Medicaid reimbursement affected Medicaid recipients' access to prescriptions or other supply side responses by manufacturers. Our results on access to drugs in targeted drug groups are inconclusive, but we do find suggestive evidence that manufacturers engaged in strategic product introductions and discontinuations that likely mitigated the profit loss induced by the policy.

The Affordable Care Act will significantly expand Medicaid enrollment and drug spending under this program, making the need for well-designed procurement rules that 
constrain distortionary behaviors and excessive spending even more critical in the near future. Despite calls for Medicaid payment reform, ${ }^{50}$ numerous AWP lawsuits, and several proposed changes to drug procurement rules, the AWP is still used as the primary reimbursement benchmark in the majority of state Medicaid programs. The persistence of the AWP reflects the significant challenges of designing alternative procurement policies that both limit distortions to market outcomes and that are feasible to implement.

\footnotetext{
${ }^{50}$ For example, see "Medicaid Prescription Drug Reimbursement: Why the Government Pays Too Much,” House
} Committee on Energy and Commerce, Subcommittee on Oversight and Investigations, 108th Congress (2004). 


\section{References}

Abramson, R. et al., 2004. Generic Drug Cost Containment in Medicaid: Lessons from Five State MAC Programs. Health Care Financing Review. 25(3): 25-34.

Berndt, E. and Aitken, M., 2010. Brand Loyalty, Generic Entry and Price Competition in Pharmaceuticals the Quarter Century after the 1984 Waxman-Hatch Legislation. NBER Working Paper 16431.

Berndt, E., McGuire T., and Newhouse, J. 2011. A Primer on the Economics of Prescription Pharmaceutical Pricing in Health Insurance Markets. Forum for Health Economics \& Policy, 14(2), Article 10.

Berndt, E. and Newhouse, J., 2012. Pricing and Reimbursement in U.S. Pharmaceutical Markets. in Patricia Danzon and Sean Nicholson, eds., The Economics of the Biopharmaceutical Industry, New York: Oxford University Press, pg. 201-265

Brekke, K., Holmas, T., and Straume, O. 2011. Reference Pricing, Competition, and Pharmaceutical Expenditures: Theory and Evidence from a Natural Experiment. Journal of Public Economics, 95(7): 624-638.

Centers for Medicare and Medicaid Services, 2013. Medicaid Covered Outpatient Prescription Drug Reimbursement Information by State, Quarter Ending March 2013. Available at http://www.medicaid.gov/Medicaid-CHIP-Program-Information/ByTopics/Benefits/Prescription-Drugs/Downloads/reimbursementchart-2Q2013.pdf

Chabner, B., 2011. Drug Shortages-A Critical Challenge for the Generic-Drug Market. New England Journal of Medicine, 365(23): 2147-2149.

Ching, A., 2010. A Dynamic Oligopoly Structural Model for the Prescription Drug Market After Patent Expiration. International Economic Review, 51(4): 1175-1207.

Congressional Budget Office, 2004. Medicaid’s Reimbursements to Pharmacies for Prescription Drugs. Available at http://www.cbo.gov/publication/16199.

Dafny, L., 2005. How Do Hospitals Respond to Price Changes? American Economic Review, 95(5): 1525-1547.

Danzon, P. et al., 2005. Alternative Strategies for Medicare Payment of Outpatient Prescription Drugs - Part B and Beyond. American Journal of Managed Care, 11(3): 173-180.

Drug Topics Red Book, 1999. Medical Economics Co., Montvale, NJ.

Duggan, M. and Scott-Morton, F., 2006. The Distortionary Effects of Government Procurement: Evidence from Medicaid Prescription Drug Purchasing. Quarterly Journal of Economics, 121(1): 1-30. 
Gruber, J. et al., 1999. Physician Fees and Procedure Intensity: The Case of Cesarean Delivery. Journal of Health Economics, 18(4): 473-490.

Grabowski, H. and Vernon, J., 1992. Brand Loyalty, Entry, and Price Competition in Pharmaceuticals after the 1984 Drug Act. Journal of Law and Economics, 35(2): 331350 .

Holmstrom, B. and Milgrom, P. 1991. Multitask Principal-Agent Analyses: Incentive Contracts, Asset Ownership, and Job Design. The Journal of Law, Economics, and Organization. 7:24-52.

Jacobson, M. et al., 2010. How Medicare’s Payment Cuts for Cancer Chemotherapy Drugs Changed Patterns of Treatment. Health Affairs, 29(7): 1394-1402.

Kaiser Family Foundation, 2002. Medicaid: Purchasing Prescription Drugs. Available at http://www.kff.org/medicaid/4025-index.cfm.

Kolassa, E., 1994. Guidance for Clinicians in Discerning and Comparing the Price of Pharmaceutical Agents. Journal of Pain and Symptom Management, 9(4): 235-243.

Kolassa, E., 1997. Elements of Pharmaceutical Pricing, Binghamton, NY: The Pharmaceutical Products Press.

National Association of State Medicaid Directors, 2010. Post AWP Pharmacy Pricing and Reimbursement. Available at http://hsd.aphsa.org/home/doc/SummaryofWhitePaper.pdf.

National Pharmaceutical Council, 2000. Pharmaceutical Benefits Under State Medical Assistance Programs. Available at http://www.npcnow.org/Public/Issues/i_rel_research/Medicaid_Pharmaceutical_Plan_Re sources.aspx.

Office of the Attorney General, Medicaid Fraud Control Unit, State of New York, 2000. Letter to Medicaid Pharmacy Director of West Virginia. Available at: http://www.doj.state.wi.us/AWP/WestVirginia/TrialExhibits/WV_PLAINTIFFS_EXHIB IT_154.pdf

Reiffen D. and Ward, M., 2005. Generic Drug Industry Dynamics. Review of Economics and Statistics, 87(1): 37-49.

Shea, M., et al., 2008. Association between the Medicare Modernization Act of 2003 and Patient Wait Times and Travel Distance for Chemotherapy. JAMA, 300(2): 189-96.

Texas Office of the Comptroller, 2003. Texas Health Care Claims Study. Available at: http://www.window.state.tx.us/specialrpt/hcc2003/ 
U.S. Department of Health and Human Services, Health Care Financing Administration, 2000. An Additional Source of Average Wholesale Price Data in Pricing Drugs and Biologicals Covered by the Medicare Program. Transmittal AB-00-86, HCFA-Pub. 60AB.

U.S. Department of Health and Human Services, Office of Inspector General, 2001. Medicaid's Use of Revised Average Wholesale Prices. Report No. OEI-03-01-00010.

U.S. Department of Health and Human Services, Office of Inspector General, 2002. Medicaid Pharmacy -- Additional Analyses of the Actual Acquisition Cost of Prescription Drug Products. Report No. A-06-02-0041.

U.S. Department of Health and Human Services, Office of Inspector General, 2004. Omission of Drugs from the Federal Upper Limit List in 2001. Report No. OEI-03-02-00670.

U.S. Department of Health and Human Services, Office of Inspector General, 2004. Addition of Qualified Drugs to the Medicaid Federal Upper Limit List. Report No. OEI-03-04-00320.

U.S. Department of Health and Human Services, Office of Inspector General, 2011. Replacing Average Wholesale Price: Medicaid Drug Payment Policy. Report No. OEI-03-11-00060.

U.S. Department of Health and Human Services, Office of Inspector General, 2012. Analyzing Changes to Medicaid Federal Upper Limit Amounts. Report No. OEI-03-11-00650.

U.S. Department of Justice (2010). "Pharmaceutical Manufacturers to Pay \$421.2 Million to Settle False Claims Act Cases.” Available at http://www.justice.gov/opa/pr/2010/December/10-civ-1398.html

U.S. Department of Justice (2012). "McKesson Corp. Pays U.S. More Than \$190 Million to Resolve False Claims Act Allegations.” Available at http://www.justice.gov/opa/pr/2012/April/12-civ-539.html

U.S. Government Accountability Office, 2001. Medicare Payments for Covered Outpatient Drugs Exceed Providers' Cost. Report No. GAO-01-1118.

U.S. Government Accountability Office, 2002. Medicare Outpatient Drugs: Program Payments Should Better Reflect Market Prices. Dummit, L. - Testimony before the US Senate Subcommittee on Health, Committee on Finance, U.S. Senate.

Yurukoglu, A., 2012. Medicare Reimbursements and Shortages of Sterile Injectable Pharmaceuticals. NBER Working Paper 17987. 
Figure 1- Trends in Reimbursement per Prescription and Prescriptions Purchased, 19912004

Panel A: Mean Reimbursement per Prescription for Targeted and Competitor NDCs
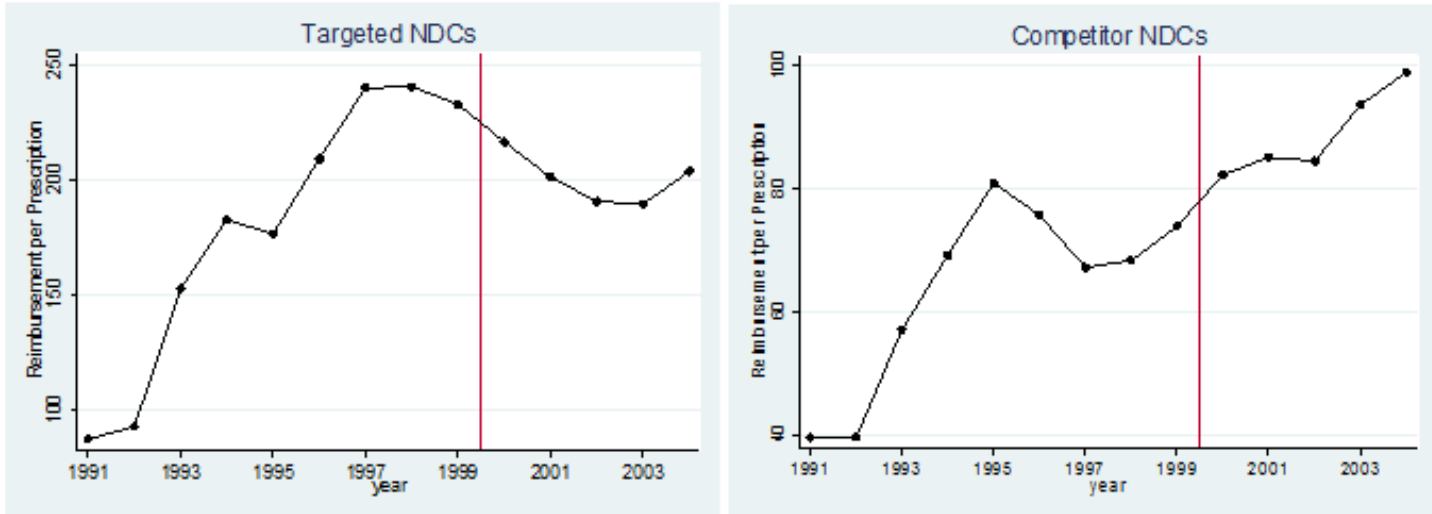

Panel B: Mean Number of Prescriptions for Targeted and Competitor NDCs
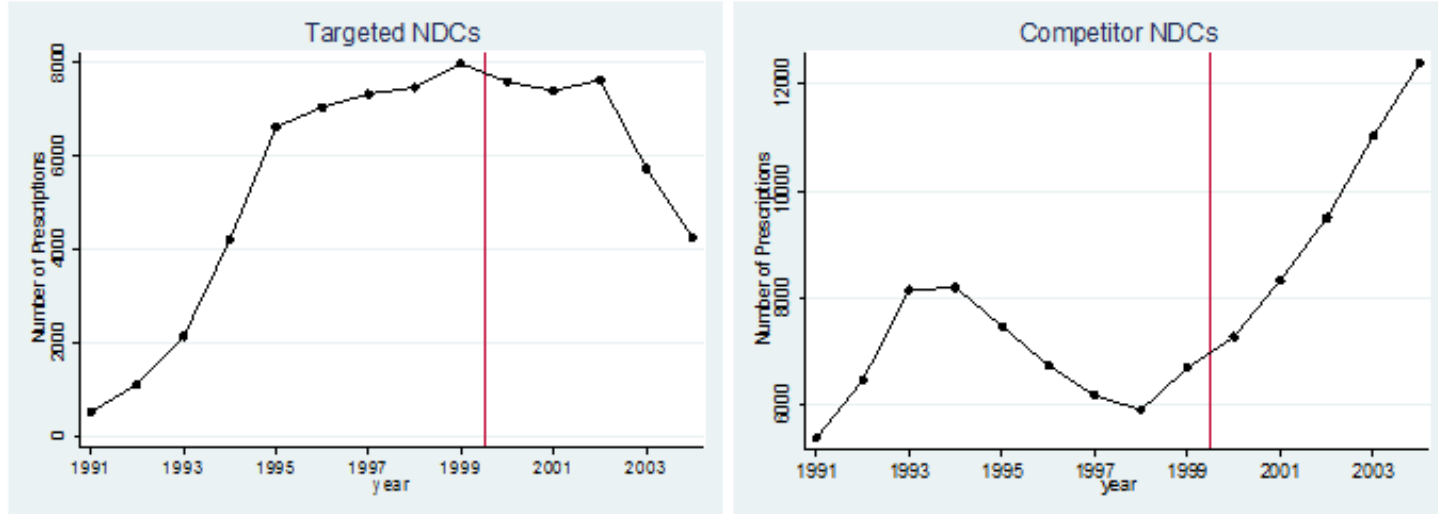

Panel C: Mean Targeted Market Share at the Drug Group Level

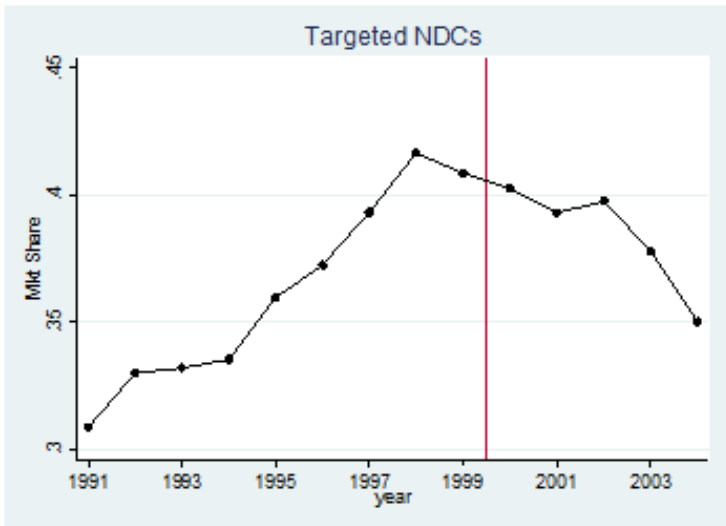

Notes: Figure 1 plots raw means of reimbursement per prescription and number of prescriptions using NDC-level data and mean targeted market share using drug group level data. Means for NDCs that were targeted by the DOJ and their competitor NDCs are plotted separately. Sample restrictions are described in section 4.2. 
Figure 2 - Trends in Prescriptions for Competitor NDCs, Targeted Firms vs. Non-Targeted Firms

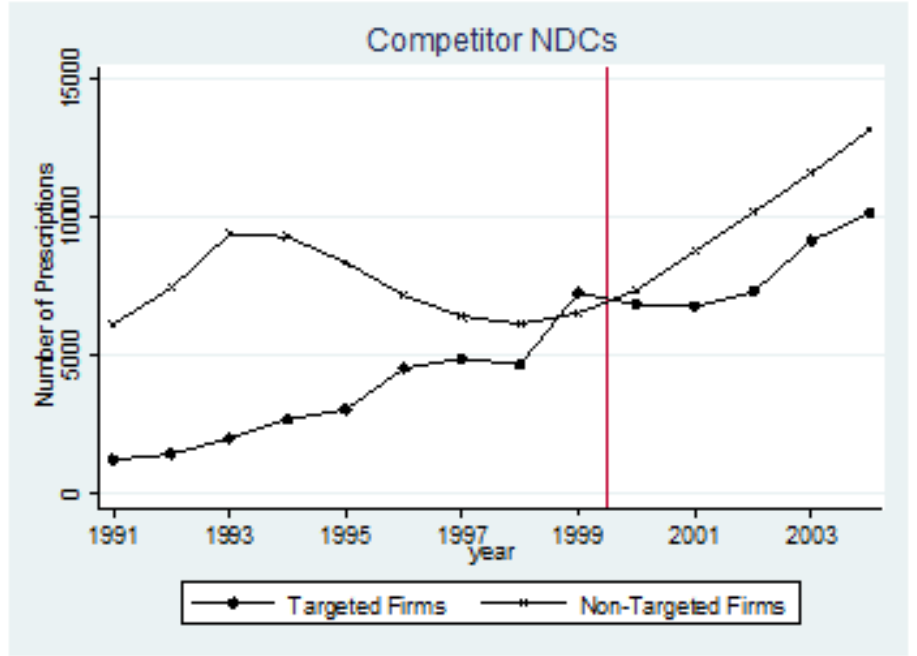

Notes: Figure 2 plots raw means of the number of prescriptions using NDC-level data for "competitor” NDCs. Means are plotted separately for competitor NDCs that were manufactured by firms whose other products in the drug group had been targeted by the DOJ with competitor NDCs that were manufactured by firms whose products were not at all targeted in the drug group. The sample excludes data from the five states that do not use the AWP as their primary reimbursement methodology, hemophilia drugs, and outliers as described in the text in section 4.2. 
Table 1 - Illustration of Margins between Published AWPs and DOJ-Audited Actual Average Wholesale Prices for Select NDCs

\begin{tabular}{lll|c|c}
\hline \hline Generic Name & NDC & Product Description & $\begin{array}{c}\text { AWP in 1999 } \\
\text { (Red Book) }\end{array}$ & $\begin{array}{c}\text { DOJ Average } \\
\text { Wholesale Price }\end{array}$ \\
\hline ACETYLCYSTEINE & $49502-0182-30$ & $20 \%, 30 \mathrm{ml}, 3 \mathrm{~s}$ & 133.43 & $\mathbf{5 0 . 6 4}$ \\
ACYCLOVIR SODIUM & $63323-0325-20$ & $50 \mathrm{mg} / \mathrm{ml}, 20 \mathrm{ml}$ & 42.59 & $\mathbf{2 8 . 0 0}$ \\
ALBUTEROL SULFATE & $49502-0697-60$ & $0.083 \%, 3 \mathrm{ml}, 60 \mathrm{~s}$ & 72.60 & $\mathbf{2 2 . 0 1}$ \\
CIMETIDINE HYDROCHLORIDE & $00074-7444-01$ & $150 \mathrm{mg} / \mathrm{ml}, 2 \mathrm{ml}, 10 \mathrm{~s}$ & 86.69 & $\mathbf{1 1 . 7 2}$ \\
CLINDAMYCIN PHOSPHATE & $00009-0728-09$ & $150 \mathrm{mg} / \mathrm{ml}, 60 \mathrm{ml}, 5 \mathrm{~s}$ & 905.88 & $\mathbf{2 5 9 . 2 0}$ \\
FUROSEMIDE & $00074-6102-04$ & $10 \mathrm{mg} / \mathrm{ml}, 4 \mathrm{ml}, 25 \mathrm{~s}$ & 122.02 & $\mathbf{2 0 . 2 8}$ \\
LORAZEPAM & $00074-1985-10$ & $2 \mathrm{mg} / \mathrm{ml}, 10 \mathrm{ml}$ & 86.81 & $\mathbf{2 5 . 8 3}$ \\
LUPRON & $00300-3629-01$ & $7.5 \mathrm{mg}$, ea $(\mathrm{PDS})$ & 594.65 & $\mathbf{4 8 2 . 5 2}$ \\
VANCOMYCIN HYDROCHLORIDE & $00205-3154-15$ & $1 \mathrm{gm}, 10 \mathrm{~s}, \mathrm{ea}$ & 109.39 & $\mathbf{9 . 0 2}$ \\
ZOFRAN & $00173-0461-00$ & $32 \mathrm{mg} / 50 \mathrm{ml}, 50 \mathrm{ml}$ & 206.41 & $\mathbf{1 2 8 . 0 9}$ \\
\hline
\end{tabular}

Notes: The source for the AWP is the 1999 Red Book; the source for the actual average wholesale price uncovered in the DOJ audit is obtained from a Program Memorandum issued by the Department of Health and Human Services (HHS, 2000). For each generic or off-patent drug shown in the table, the NDC selected represents approximately the median spread (ratio of Red Book AWP to DOJ average wholesale price) for that drug group. 
Table 2 - Descriptive Statistics, 1999-2002

\begin{tabular}{|c|c|c|c|c|}
\hline \multirow[b]{3}{*}{ Sample: } & Targeted NDCs & \multicolumn{3}{|c|}{ Competitor NDCs } \\
\hline & \multirow[b]{2}{*}{ (1) } & All & $\begin{array}{c}\text { Targeted } \\
\text { Firms }\end{array}$ & $\begin{array}{c}\text { Non-Targeted } \\
\text { Firms }\end{array}$ \\
\hline & & $(2)$ & $(3)$ & $(4)$ \\
\hline Reimbursement per Prescription, 1999 & 232.61 & 73.86 & 166.67 & 50.49 \\
\hline Change in Reimbursement per Prescription, 1999-2002 & -42.13 & 10.72 & -16.66 & 12.73 \\
\hline Number of Prescriptions, 1999 & 7,994.12 & 6,699.91 & $7,288.44$ & 6,551.67 \\
\hline Change in Number of Prescriptions, 1999-2002 & -358.17 & $2,803.16$ & 37.15 & $3,662.51$ \\
\hline NDC Market Share, 1999 & 0.050 & 0.009 & 0.011 & 0.009 \\
\hline Change in NDC Market Share, 1999-2002 & 0.001 & 0.002 & 0.001 & 0.002 \\
\hline Drug Group Market Share, 1999* & 0.409 & 0.635 & 0.188 & 0.566 \\
\hline Change in Drug Group Market Share, 1999-2002 & -0.011 & -0.018 & 0.004 & -0.032 \\
\hline Fraction Generic, 1999 & 0.670 & 0.787 & 0.639 & 0.841 \\
\hline Year of FDA Approval, 1999 & 1991.3 & 1989.6 & 1990.7 & 1989.2 \\
\hline \multicolumn{5}{|l|}{ Fraction Unit Type, 1999: } \\
\hline ML & 0.737 & 0.466 & 0.763 & 0.358 \\
\hline Gram & 0.024 & 0.046 & 0.029 & 0.053 \\
\hline Capsule & 0.000 & 0.023 & 0.016 & 0.025 \\
\hline Tablet & 0.000 & 0.374 & 0.110 & 0.470 \\
\hline Other & 0.239 & 0.091 & 0.082 & 0.094 \\
\hline Total Prescriptions, 1999 & $2,869,890$ & $18,980,848$ & $4,154,410$ & $14,826,438$ \\
\hline Total Reimbursement, 1999 & $155,787,680$ & $389,058,079$ & $107,581,483$ & $281,476,595$ \\
\hline NDC x Year Observations, 1999 & 359 & 2,833 & 570 & 2,263 \\
\hline
\end{tabular}

Notes: Variable means are reported using NDC-level data with the exception of drug group market share*, which uses drug group-level data. The sample excludes data from the five states that do not use the AWP as their primary reimbursement methodology, hemophilia drugs, and outliers as described in the text in section 4.2. 
Table 3- Effects of DOJ Intervention on Reimbursement per Prescription, 1994-2004

\begin{tabular}{|c|c|c|c|c|}
\hline \multirow[t]{2}{*}{ Dependent variable: } & \multicolumn{4}{|c|}{ Log (Reimbursement per Prescription) } \\
\hline & (1) & $(2)$ & (3) & (4) \\
\hline Target*Post*(t-2000) & & $\begin{array}{l}-0.071^{*} \\
(0.041)\end{array}$ & $\begin{array}{c}-0.092 * * \\
(0.038)\end{array}$ & $\begin{array}{c}-0.110^{* *} \\
(0.047)\end{array}$ \\
\hline Target*Post & & $\begin{array}{c}-0.292 * * * \\
(0.055)\end{array}$ & $\begin{array}{c}-0.325^{* * *} \\
(0.052)\end{array}$ & $\begin{array}{c}-0.343^{* * *} \\
(0.061)\end{array}$ \\
\hline Target*Year1994 & $\begin{array}{c}0.109 \\
(0.139)\end{array}$ & & & \\
\hline Target*Year1995 & $\begin{array}{c}0.025 \\
(0.120)\end{array}$ & & & \\
\hline Target*Year1996 & $\begin{array}{c}0.100 \\
(0.122)\end{array}$ & & & \\
\hline Target*Year1997 & $\begin{array}{c}0.127 \\
(0.107)\end{array}$ & & & \\
\hline Target*Year1998 & $\begin{array}{c}0.059 \\
(0.048)\end{array}$ & & & \\
\hline Target*Year2000 & $\begin{array}{c}-0.175^{* * *} \\
(0.039)\end{array}$ & & & \\
\hline Target*Year2001 & $\begin{array}{c}-0.421^{* * *} \\
(0.076)\end{array}$ & & & \\
\hline Target*Year2002 & $\begin{array}{c}-0.525^{* * *} \\
(0.087)\end{array}$ & & & \\
\hline Target*Year2003 & $\begin{array}{c}-0.543^{* * *} \\
(0.088)\end{array}$ & & & \\
\hline Target*Year2004 & $\begin{array}{c}-0.528^{* * *} \\
(0.090)\end{array}$ & & & \\
\hline Year FE & $\mathrm{Y}$ & $\mathrm{Y}$ & $\mathrm{Y}$ & $\mathrm{Y}$ \\
\hline NDC FE & Y & $\mathrm{Y}$ & $\mathrm{Y}$ & $\mathrm{Y}$ \\
\hline Drug Group x Target x t & $\mathrm{N}$ & $\mathrm{N}$ & $\mathrm{Y}$ & $\mathrm{Y}$ \\
\hline Excl. Targeted Firms & $\mathrm{N}$ & $\mathrm{N}$ & $\mathrm{N}$ & $\mathrm{Y}$ \\
\hline F-test & $\begin{array}{l}11.390 \\
{[0.000]}\end{array}$ & & & \\
\hline NDC x Year Obs & 32,203 & 32,203 & 32,203 & 26,899 \\
\hline
\end{tabular}

Notes: ${ }^{* * *} \mathrm{p}<0.01,{ }^{* *} \mathrm{p}<0.05,{ }^{*} \mathrm{p}<0.1$. Clustered standard errors at the drug group level. Column 1 reports results from estimating equation 2 using NDC-level data and Columns 2-4 report results from estimating equation 3 and 4. Column 2 also includes a linear time trend interacted with Target which is not reported. Column 3 adds Drug Group $\mathrm{x}$ Target specific linear trends, and Column 4 excludes observations from "competitor” NDCs manufactured by targeted firms. The F-test tests the joint significance of Target*Year2000 through Target*Year2004 (p-value in brackets). Sample restrictions are described in section 4.2 . 
Table 4 - Effects of DOJ Intervention on Prescriptions Purchased, 1994-2004

\begin{tabular}{|c|c|c|c|c|c|}
\hline \multirow[t]{3}{*}{ Dependent variable: } & \multicolumn{3}{|c|}{ Targeted Market Share } & \multicolumn{2}{|c|}{ Competitor Market Share } \\
\hline & & & & $\begin{array}{c}\text { Targeted } \\
\text { Firms } \\
\end{array}$ & $\begin{array}{c}\text { Non-Targeted } \\
\text { Firms }\end{array}$ \\
\hline & (1) & $(2)$ & (3) & (4) & $(5)$ \\
\hline Post* $*(t-2000)$ & & $\begin{array}{c}-0.036 * * \\
(0.014)\end{array}$ & $\begin{array}{c}-0.037 * * \\
(0.015)\end{array}$ & $\begin{array}{c}0.002 \\
(0.010)\end{array}$ & $\begin{array}{c}0.035 * * \\
(0.016)\end{array}$ \\
\hline Post & & $\begin{array}{c}-0.04 \\
(0.027)\end{array}$ & $\begin{array}{c}-0.04 \\
(0.029)\end{array}$ & $\begin{array}{c}0.022 \\
(0.018)\end{array}$ & $\begin{array}{c}0.019 \\
(0.024)\end{array}$ \\
\hline Year1994 & $\begin{array}{c}-0.110 * * \\
(0.050)\end{array}$ & & & & \\
\hline Year1995 & $\begin{array}{l}-0.080 * \\
(0.046)\end{array}$ & & & & \\
\hline Year1996 & $\begin{array}{l}-0.052 \\
(0.041)\end{array}$ & & & & \\
\hline Year1997 & $\begin{array}{l}-0.014 \\
(0.027)\end{array}$ & & & & \\
\hline Year1998 & $\begin{array}{l}-0.001 \\
(0.023)\end{array}$ & & & & \\
\hline Year2000 & $\begin{array}{l}-0.006 \\
(0.017)\end{array}$ & & & & \\
\hline Year2001 & $\begin{array}{l}-0.015 \\
(0.023)\end{array}$ & & & & \\
\hline Year2002 & $\begin{array}{l}-0.011 \\
(0.028)\end{array}$ & & & & \\
\hline Year2003 & $\begin{array}{l}-0.039 \\
(0.033)\end{array}$ & & & & \\
\hline Year2004 & $\begin{array}{r}-0.058 \\
(0.041) \\
\end{array}$ & & & & \\
\hline Drug Group FE & $\mathrm{Y}$ & $\mathrm{Y}$ & $\mathrm{Y}$ & $\mathrm{Y}$ & $\mathrm{Y}$ \\
\hline Drug Group x t & $\mathrm{N}$ & $\mathrm{N}$ & $\mathrm{Y}$ & $\mathrm{Y}$ & $\mathrm{Y}$ \\
\hline F-test & $\begin{array}{c}2.230 \\
{[0.068]}\end{array}$ & & & & \\
\hline Mean Dependent & & & & & \\
\hline Variable (1999) & 0.409 & & & 0.141 & 0.450 \\
\hline Observations & 480 & 480 & 480 & 480 & 480 \\
\hline
\end{tabular}

Notes: ${ }^{* * *} \mathrm{p}<0.01,{ }^{* *} \mathrm{p}<0.05,{ }^{*} \mathrm{p}<0.1$. Clustered standard errors at the drug group level. Column 1 reports results from estimating equation 5 using drug group-level data and Columns 2 and 3 report results from estimating equation 6. Column 2 is estimated at the drug group level and includes a linear time trend whose coefficient is not reported. Column 3 adds drug group specific linear trends. Columns 4 and 5 report results using the market share of competitor drugs (for targeted firms or non-targeted firms) as the dependent variable. The F-test tests the joint significance of Year2000 through Year2004 (p-value in brackets). Sample restrictions are described in section 4.2. 
Table 5 - Early Adopter States versus All Other States

\begin{tabular}{|c|c|c|c|c|c|}
\hline \multirow[t]{3}{*}{ Dependent variable: } & \multicolumn{2}{|c|}{$\begin{array}{c}\text { Log (Reimbursement per } \\
\text { Prescription) }\end{array}$} & & \multicolumn{2}{|c|}{ Targeted Market Share } \\
\hline & $\begin{array}{l}\text { Early Adopter } \\
\text { States } \\
\end{array}$ & $\begin{array}{l}\text { All Other } \\
\text { States }\end{array}$ & & $\begin{array}{l}\text { Early Adopter } \\
\text { States }\end{array}$ & $\begin{array}{c}\text { All Other } \\
\text { States }\end{array}$ \\
\hline & $(1)$ & $(2)$ & & (3) & $(4)$ \\
\hline Target*Year1994 & $\begin{array}{c}0.124 \\
(0.140)\end{array}$ & $\begin{array}{l}-0.018 \\
(0.148)\end{array}$ & Year1994 & $\begin{array}{c}-0.117 * * \\
(0.051)\end{array}$ & $\begin{array}{l}-0.095^{*} \\
(0.050)\end{array}$ \\
\hline Target*Year1995 & $\begin{array}{c}0.089 \\
(0.128)\end{array}$ & $\begin{array}{l}-0.039 \\
(0.148)\end{array}$ & Year1995 & $\begin{array}{l}-0.084^{*} \\
(0.047)\end{array}$ & $\begin{array}{l}-0.071 \\
(0.047)\end{array}$ \\
\hline Target*Year1996 & $\begin{array}{c}0.101 \\
(0.127)\end{array}$ & $\begin{array}{c}0.024 \\
(0.134)\end{array}$ & Year1996 & $\begin{array}{l}-0.056 \\
(0.041)\end{array}$ & $\begin{array}{l}-0.042 \\
(0.042)\end{array}$ \\
\hline Target*Year1997 & $\begin{array}{c}0.128 \\
(0.105)\end{array}$ & $\begin{array}{c}0.081 \\
(0.125)\end{array}$ & Year1997 & $\begin{array}{l}-0.018 \\
(0.027)\end{array}$ & $\begin{array}{l}-0.015 \\
(0.032)\end{array}$ \\
\hline Target*Year1998 & $\begin{array}{c}0.047 \\
(0.043)\end{array}$ & $\begin{array}{c}0.008 \\
(0.063)\end{array}$ & Year1998 & $\begin{array}{l}-0.007 \\
(0.021)\end{array}$ & $\begin{array}{c}0.01 \\
(0.025)\end{array}$ \\
\hline Target*Year2000 & $\begin{array}{c}-0.310^{* * *} \\
(0.060)\end{array}$ & $\begin{array}{c}-0.099 * * \\
(0.046)\end{array}$ & Year2000 & $\begin{array}{l}-0.021 \\
(0.021)\end{array}$ & $\begin{array}{c}0.008 \\
(0.017)\end{array}$ \\
\hline Target*Year2001 & $\begin{array}{c}-0.660^{* * *} \\
(0.112)\end{array}$ & $\begin{array}{c}-0.215^{* * *} \\
(0.057)\end{array}$ & Year2001 & $\begin{array}{l}-0.039 \\
(0.026)\end{array}$ & $\begin{array}{c}0.021 \\
(0.024)\end{array}$ \\
\hline Target*Year2002 & $\begin{array}{c}-0.630^{* * *} \\
(0.111)\end{array}$ & $\begin{array}{c}-0.437 * * * \\
(0.090)\end{array}$ & Year2002 & $\begin{array}{l}-0.047 \\
(0.031)\end{array}$ & $\begin{array}{c}0.033 \\
(0.030)\end{array}$ \\
\hline Target*Year2003 & $\begin{array}{c}-0.583 * * * \\
(0.099)\end{array}$ & $\begin{array}{c}-0.484 * * * \\
(0.102)\end{array}$ & Year2003 & $\begin{array}{l}-0.062 * \\
(0.034)\end{array}$ & $\begin{array}{l}-0.011 \\
(0.039)\end{array}$ \\
\hline Target*Year2004 & $\begin{array}{c}-0.548^{* * *} \\
(0.100)\end{array}$ & $\begin{array}{c}-0.507^{* * *} \\
(0.108)\end{array}$ & Year2004 & $\begin{array}{c}-0.088 * * \\
(0.040)\end{array}$ & $\begin{array}{l}-0.025 \\
(0.046)\end{array}$ \\
\hline Year FE & $\mathrm{Y}$ & $\mathrm{Y}$ & Drug Group FE & $\mathrm{Y}$ & $\mathrm{Y}$ \\
\hline NDC FE & $\mathrm{Y}$ & $\mathrm{Y}$ & Drug Group x t & $\mathrm{N}$ & $\mathrm{N}$ \\
\hline Drug Group x Target x t & $\mathrm{N}$ & $\mathrm{N}$ & & & \\
\hline F-test & $\begin{array}{c}7.800 \\
{[0.000]} \\
\end{array}$ & $\begin{array}{l}10.420 \\
{[0.000]} \\
\end{array}$ & F-test & $\begin{array}{l}1.460 \\
{[0.223]}\end{array}$ & $\begin{array}{l}1.980 \\
{[0.101]}\end{array}$ \\
\hline NDC x Year Obs & 29,038 & 29,254 & Drug Group x Year Obs & 480 & 480 \\
\hline
\end{tabular}


Table 6 - Heterogeneous Treatment Effects

\begin{tabular}{|c|c|c|c|c|c|c|c|c|}
\hline & \multicolumn{2}{|c|}{ Baseline } & \multicolumn{2}{|c|}{$\begin{array}{c}\text { Targeted Market Share } \\
\text { in Drug Group (1999) }\end{array}$} & \multicolumn{2}{|c|}{$\begin{array}{l}\text { Targeted Spread in } \\
\text { Drug Group (1999) }\end{array}$} & \multicolumn{2}{|c|}{$\begin{array}{l}\text { Number of Firms in } \\
\text { Drug Group (1999) }\end{array}$} \\
\hline & (1) & $(2)$ & (3) & (4) & (5) & (6) & (7) & $(8)$ \\
\hline \multicolumn{9}{|c|}{ Panel A: Log (Reimbursement per Prescription) } \\
\hline Target*Post*(t-2000) & $\begin{array}{c}-0.092 * * \\
(0.035)\end{array}$ & $\begin{array}{c}-0.101^{* * *}= \\
(0.030)\end{array}$ & $\begin{array}{c}-0.102 * * * \\
(0.033)\end{array}$ & $\begin{array}{c}-0.113 * * * \\
(0.032)\end{array}$ & $\begin{array}{c}-0.09 \\
(0.059)\end{array}$ & $\begin{array}{l}-0.102 * \\
(0.057)\end{array}$ & $\begin{array}{c}-0.105^{* *} \\
(0.048)\end{array}$ & $\begin{array}{c}-0.119 * * \\
(0.043)\end{array}$ \\
\hline Target*Post & $\begin{array}{c}-0.325 * * * \\
(0.048)\end{array}$ & $\begin{array}{c}-0.288 * * * \\
(0.055)\end{array}$ & $\begin{array}{c}-0.387 * * * \\
(0.049)\end{array}$ & $\begin{array}{c}-0.387 * * * \\
(0.060)\end{array}$ & $\begin{array}{l}-0.114^{*} \\
(0.066)\end{array}$ & $\begin{array}{c}-0.07 \\
(0.091)\end{array}$ & $\begin{array}{c}-0.324 * * * \\
(0.092)\end{array}$ & $\begin{array}{c}-0.276^{* *} \\
(0.102)\end{array}$ \\
\hline Target*Post*(t-2000)*I(>Median) & & & $\begin{array}{c}0.016 \\
(0.041)\end{array}$ & $\begin{array}{c}0.017 \\
(0.045)\end{array}$ & $\begin{array}{l}-0.003 \\
(0.055)\end{array}$ & $\begin{array}{c}0.000 \\
(0.062)\end{array}$ & $\begin{array}{c}0.026 \\
(0.041)\end{array}$ & $\begin{array}{c}0.036 \\
(0.044)\end{array}$ \\
\hline Target*Post*I(>Median) & & & $\begin{array}{r}0.106 \\
(0.100) \\
\end{array}$ & $\begin{array}{c}0.148 \\
(0.114) \\
\end{array}$ & $\begin{array}{c}-0.294 * * * \\
(0.079) \\
\end{array}$ & $\begin{array}{c}-0.305^{* * *} \\
(0.100) \\
\end{array}$ & $\begin{array}{r}0.000 \\
(0.106) \\
\end{array}$ & $\begin{array}{l}-0.021 \\
(0.124) \\
\end{array}$ \\
\hline $\begin{array}{l}\text { Trimmed (Excl. Targeted Mkt She } \\
<5 \% \text { \& }>95 \% \text { ) }\end{array}$ & $\mathrm{N}$ & $\mathrm{Y}$ & $\mathrm{N}$ & $\mathrm{Y}$ & $\mathrm{N}$ & $\mathrm{Y}$ & $\mathrm{N}$ & $\mathrm{Y}$ \\
\hline NDC x Year Obs & 32,203 & 15,758 & 32,203 & 15,758 & 32,060 & 15,725 & 32,203 & 15,758 \\
\hline \multicolumn{9}{|l|}{ Panel B: Targeted Market Share } \\
\hline Post*(t-2000) & $\begin{array}{c}-0.037 * * \\
(0.015)\end{array}$ & $\begin{array}{c}-0.040 * * \\
(0.019)\end{array}$ & $\begin{array}{c}0.004 \\
(0.015)\end{array}$ & $\begin{array}{c}0.006 \\
(0.027)\end{array}$ & $\begin{array}{l}-0.031 \\
(0.024)\end{array}$ & $\begin{array}{l}-0.014 \\
(0.024)\end{array}$ & $\begin{array}{l}-0.045 \\
(0.028)\end{array}$ & $\begin{array}{l}-0.032 \\
(0.031)\end{array}$ \\
\hline Post & $\begin{array}{c}-0.04 \\
(0.029)\end{array}$ & $\begin{array}{r}-0.046 \\
(0.039)\end{array}$ & $\begin{array}{c}0.011 \\
(0.028)\end{array}$ & $\begin{array}{c}0.009 \\
(0.051)\end{array}$ & $\begin{array}{c}-0.05 \\
(0.046)\end{array}$ & $\begin{array}{l}-0.033 \\
(0.053)\end{array}$ & $\begin{array}{l}-0.078 \\
(0.052)\end{array}$ & $\begin{array}{l}-0.075 \\
(0.061)\end{array}$ \\
\hline Post*(t-2000)*I(>Median) & & & $\begin{array}{c}-0.084 * * * \\
(0.026)\end{array}$ & $\begin{array}{c}-0.077^{* *} \\
(0.035)\end{array}$ & $\begin{array}{c}-0.02 \\
(0.030)\end{array}$ & $\begin{array}{l}-0.069 * \\
(0.034)\end{array}$ & $\begin{array}{c}0.015 \\
(0.030)\end{array}$ & $\begin{array}{c}-0.02 \\
(0.034)\end{array}$ \\
\hline Post*I(>Median) & & & $\begin{array}{l}-0.106^{*} \\
(0.055) \\
\end{array}$ & $\begin{array}{l}-0.091 \\
(0.074) \\
\end{array}$ & $\begin{array}{r}0.025 \\
(0.057) \\
\end{array}$ & $\begin{array}{l}-0.006 \\
(0.077) \\
\end{array}$ & $\begin{array}{r}0.074 \\
(0.056) \\
\end{array}$ & $\begin{array}{r}0.068 \\
(0.072) \\
\end{array}$ \\
\hline $\begin{array}{l}\text { Trimmed (Excl. Targeted Mkt Sha } \\
<5 \% \text { \& }>95 \% \text { ) }\end{array}$ & $\mathrm{N}$ & $\mathrm{Y}$ & $\mathrm{N}$ & $\mathrm{Y}$ & $\mathrm{N}$ & $\mathrm{Y}$ & $\mathrm{N}$ & $\mathrm{Y}$ \\
\hline Drug Group x Year Obs & 480 & 330 & 480 & 330 & 458 & 319 & 480 & 330 \\
\hline & & $\begin{array}{l}=\text { Median: } \\
\text { >Median: }\end{array}$ & $\begin{array}{c}\text { Mean Tar } \\
\text { Share } \\
0.10 \\
0.71\end{array}$ & $\begin{array}{l}\text { eted Mkt } \\
\text { 1999) }\end{array}$ & $\begin{array}{c}\text { Mean T } \\
\text { Spread } \\
2.21 \\
27.43\end{array}$ & $\begin{array}{l}\text { argeted } \\
\text { (1999) }\end{array}$ & $\begin{array}{c}\text { Mean No. } \\
\text { (199 } \\
2.95 \\
24.41\end{array}$ & $\begin{array}{l}\text { of Firms } \\
\text { 9) }\end{array}$ \\
\hline
\end{tabular}

Notes: ${ }^{* * *} \mathrm{p}<0.01,{ }^{* *} \mathrm{p}<0.05,{ }^{*} \mathrm{p}<0.1$. Clustered standard errors at the drug group level. Panel A includes drug group fixed effects, year fixed effects, and drug group $\mathrm{x}$ target linear trends. Panel B includes drug group fixed effects and drug group specific linear trends. Columns 1 and 2 are copied from Tables 3 and 4 . Columns 3-8 interact the slope and intercept terms of the baseline specification with an indicator for drug group characteristics: 1 ) whether the drug group had above median targeted market share in 1999 (Cols 3 and 4), 2) whether the drug group had above median average spread for targeted drugs in 1999 (Cols 5 and 6), 3) whether the drug group had above median number of competitor firms in 1999 (Cols 7 and 8). Sample restrictions are described in section 4.2. 
Table 7 - Effect on Access to Prescription Drugs and Total Spending

\begin{tabular}{lc|c}
\hline \hline Dependent Variable: & Log (Total Prescriptions) & Log (Total Reimbursement) \\
\cline { 2 - 3 } & $(1)$ & $(2)$ \\
\hline \multirow{2}{*}{ Post*(t-2000) } & -0.034 & $-0.124^{* *}$ \\
& $(0.035)$ & $(0.051)$ \\
Post & -0.007 & -0.008 \\
& $(0.061)$ & $(0.122)$ \\
\hline Drug Group FE & $\mathrm{Y}$ & $\mathrm{Y}$ \\
Drug Group x & $\mathrm{Y}$ & $\mathrm{Y}$ \\
\hline Observations & 480 & 480 \\
\hline
\end{tabular}

Notes: $* * * \mathrm{p}<0.01,{ }^{* *} \mathrm{p}<0.05,{ }^{*} \mathrm{p}<0.1$. Clustered standard errors at the drug group level. Sample restrictions are described in section 4.2. 
Table 8 - Effects on Introduction and Discontinuation of Competitor NDCs, Targeted Firms vs. Non-Targeted Firms

\begin{tabular}{|c|c|c|c|}
\hline & $\begin{array}{c}\text { Pre-DOJ } \\
\text { Intervention }\end{array}$ & $\begin{array}{c}\text { Post-DOJ } \\
\text { Intervention }\end{array}$ & Difference \\
\hline Sample: Competitor NDCs & $(1)$ & $(2)$ & (3) \\
\hline \multicolumn{4}{|c|}{ Panel A: Rate of NDC Introduction } \\
\hline Targeted Firms & $\begin{array}{c}0.473 \\
(0.207)\end{array}$ & $\begin{array}{c}0.123 \\
(0.036)\end{array}$ & $\begin{array}{c}-0.350 * \\
(0.207)\end{array}$ \\
\hline Non-Targeted Firms & $\begin{array}{c}0.856 \\
(0.307)\end{array}$ & $\begin{array}{c}0.287 \\
(0.065)\end{array}$ & $\begin{array}{l}-0.569 * \\
(0.302)\end{array}$ \\
\hline Difference-in-Difference & & & $\begin{array}{c}0.219 \\
(0.366)\end{array}$ \\
\hline \multicolumn{4}{|c|}{ Panel B: Rate of NDC Dis continuation } \\
\hline Targeted Firms & $\begin{array}{c}0.072 \\
(0.025)\end{array}$ & $\begin{array}{c}0.166 \\
(0.042)\end{array}$ & $\begin{array}{c}0.094 * * \\
(0.046)\end{array}$ \\
\hline Non-Targeted Firms & $\begin{array}{c}0.233 \\
(0.052)\end{array}$ & $\begin{array}{c}0.384 \\
(0.066)\end{array}$ & $\begin{array}{c}0.150 * \\
(0.083)\end{array}$ \\
\hline Difference-in-Difference & & & $\begin{array}{l}-0.056 \\
(0.091)\end{array}$ \\
\hline
\end{tabular}

Notes: $* * * \mathrm{p}<0.01, * * \mathrm{p}<0.05,{ }^{*} \mathrm{p}<0.1$. Clustered standard errors at the drug-group level. Each observation in the regression is a drug group $\mathrm{x}$ targeted firm cell. For the introduction results (Panel A), each cell in Column 1 reports the average (across drug groups) of the ratio of the number of NDCs in each drug group that entered in 1996-1998 (pre-DOJ intervention) divided by the number of NDCs with positive sales in the drug group in 1995 (separately for NDCs produced by targeted and non-targeted firms). Column 2 reports the average ratio of the number of NDCs in a drug group that entered in 2000-2000 divided by the baseline stock, using 1999 as the base year. The discontinuation results (Panel B) are reported similarly. Sample restrictions are described in section 4.2. N=131. 


\section{Appendix A}

\section{Figure A.1 - Illustration of DOJ Intervention for Acetylcysteine}

\section{Drug Group: Acetylcysteine}

\begin{tabular}{|lllc|}
\hline NDC & Product Description & Manufacturer & Targeted by DOJ? \\
\hline 00074-3307-01 & ACETYLCYSTEINE 10\% VIAL & Abbott (generic) & $\mathrm{N}$ \\
00074-3307-02 & ACETYLCYSTEINE 10\% VIAL & Abbott (generic) & $\mathrm{N}$ \\
00074-3307-03 & ACETYLCYSTEINE 10\% VIAL & Abbott (generic) & $\boldsymbol{Y}$ \\
00074-3308-01 & ACETYLCYSTEINE 20\% VIAL & Abbott (generic) & $\mathrm{N}$ \\
00074-3308-02 & ACETYLCYSTEINE 20\% VIAL & Abbott (generic) & $\mathrm{N}$ \\
00074-3308-03 & ACETYLCYSTEINE 20\% VIAL & Abbott (generic) & $\boldsymbol{Y}$ \\
\hline 55390-0211-03 & ACETYLCYSTEINE 10\% VIAL & Bedford (generic) & $\mathrm{N}$ \\
55390-0212-03 & ACETYLCYSTEINE 10\% VIAL & Bedford (generic) & $\mathrm{N}$ \\
55390-0213-03 & ACETYLCYSTEINE 20\% VIAL & Bedford (generic) & $\mathrm{N}$ \\
55390-0214-03 & ACETYLCYSTEINE 20\% VIAL & Bedford (generic) & N \\
\hline 61703-0203-04 & ACETYLCYSTEINE 10\% VIAL & Faulding (generic) & $\mathbf{Y}$ \\
61703-0203-31 & ACETYLCYSTEINE 10\% VIAL & Faulding (generic) & $\boldsymbol{Y}$ \\
61703-0204-04 & ACETYLCYSTEINE 20\% VIAL & Faulding (generic) & $\mathbf{Y}$ \\
61703-0204-31 & ACETYLCYSTEINE 20\% VIAL & Faulding (generic) & $\mathbf{Y}$ \\
And Other NDCs... & & \\
\hline
\end{tabular}

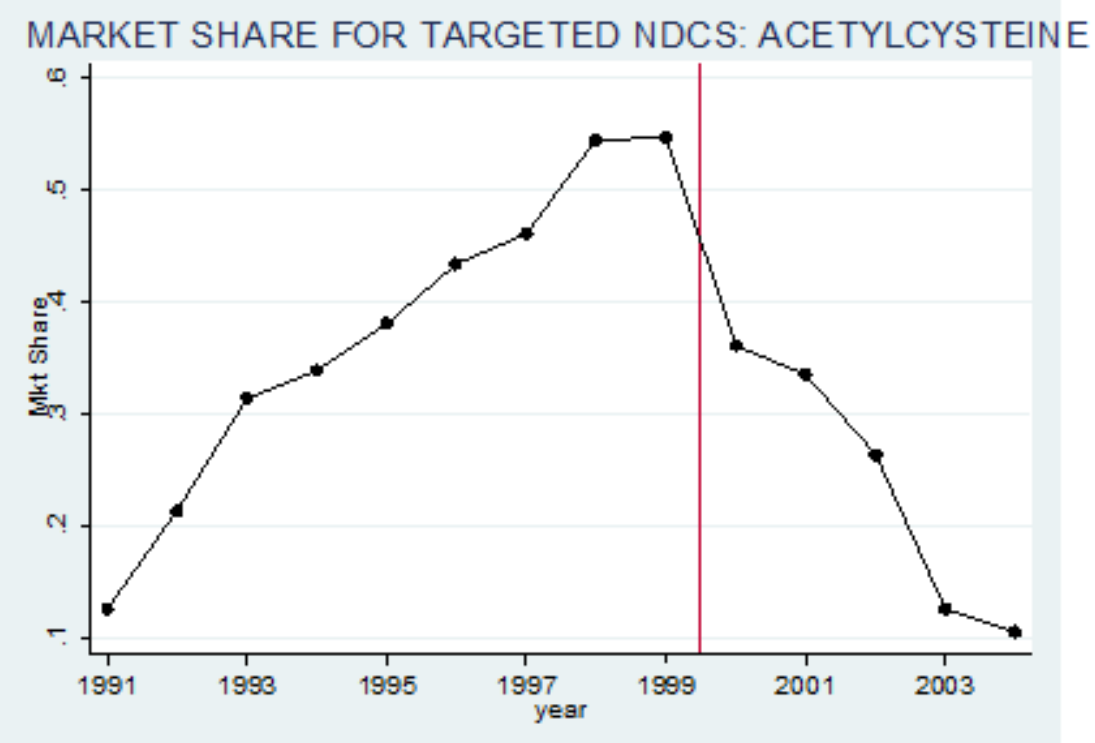

Notes: This figure illustrates the DOJ intervention described in Section 3.1 for selected NDCs within the drug group Acetylcysteine. Only a few NDCs produced by Abbott were targeted by the DOJ, all NDCs produced by Faulding were targeted, and no NDCs produced by Bedford were targeted. The DOJ recommended that states lower Medicaid reimbursement from the AWP to the audited price for targeted NDCs within the group of bioequivalent NDCs. Following the intervention, the market share for the Acetylcysteine NDCs targeted by the DOJ declined sharply. Approximately 50 drug groups had at least one NDC targeted by the DOJ, with about 400 NDCs targeted overall. 
Figure A.2 - Trends in Access to Prescription Drugs and Total Spending for Targeted Drug Groups, 1991-2004

Panel A: Log Total Prescriptions

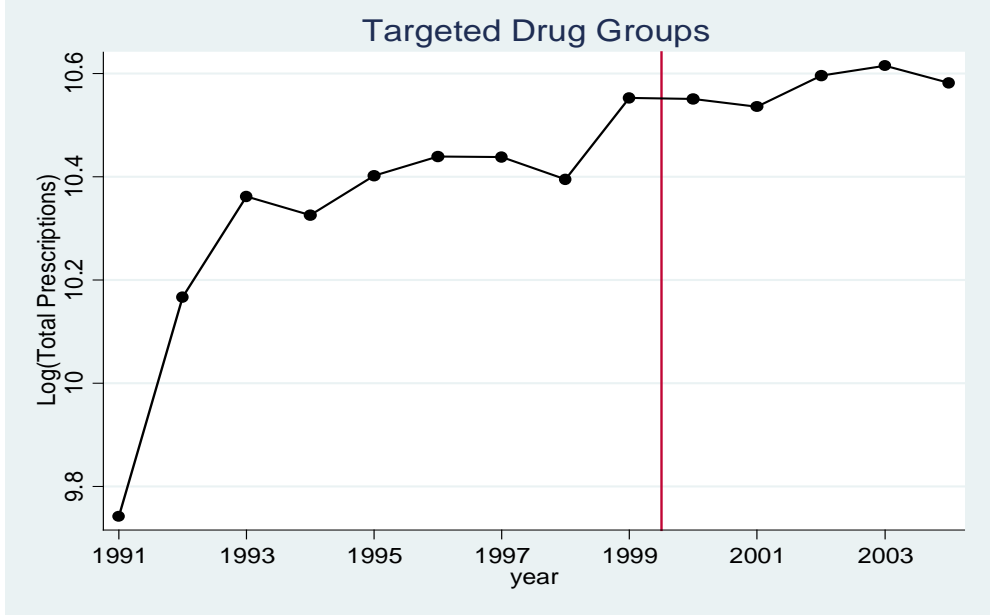

Panel B: Log Total Reimbursement

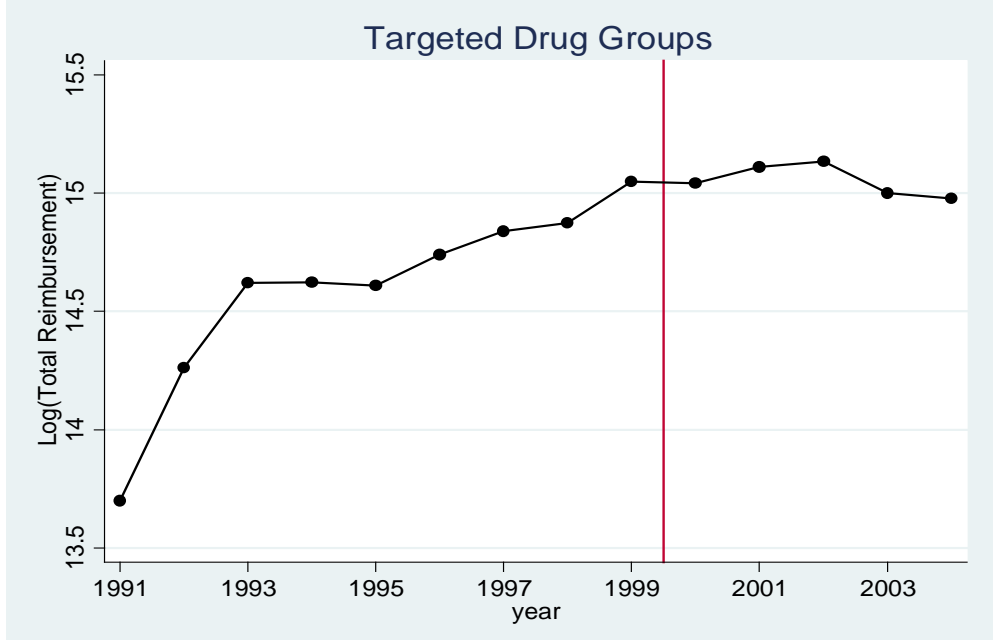

Notes: This figure plots raw means of log total number of prescriptions and log total reimbursement using drug group level data. This is the graphical analog to the regressions in Table 7. Sample restrictions are described in section 4.2 . 
Table A.1 - Descriptive Statistics for Generic Drug Groups Targeted by the DOJ, 1999

\begin{tabular}{|c|c|c|c|c|c|}
\hline Generic Drug Group & $\begin{array}{c}\text { Targeted by } \\
\text { DOJ? }\end{array}$ & $\begin{array}{c}\text { Mean } \\
\text { Reimbursement } \\
\text { per Prescription } \\
\end{array}$ & $\begin{array}{c}\text { Total Medicaid } \\
\text { Reimbursement } \\
\text { Amount (\$1000s) } \\
\end{array}$ & \begin{tabular}{c|} 
Total Number of \\
Prescriptions
\end{tabular} & \begin{tabular}{|c} 
Total Reimbursement \\
Amount for Drug \\
Group (\$1000s)
\end{tabular} \\
\hline ALBUTEROL SULFATE & $\mathrm{N}$ & 17.4 & 87,179 & $5,560,183$ & 146,139 \\
\hline ALBUTEROL SULFATE & $\mathrm{Y}$ & 32.2 & 58,960 & $1,976,543$ & 146,139 \\
\hline FACTOR VIII & $\mathrm{N}$ & 13036.1 & 951 & 40 & 97,551 \\
\hline FACTOR VIII & $\mathrm{Y}$ & 10493.2 & 96,600 & 9,697 & 97,551 \\
\hline LORAZEPAM & $\mathrm{N}$ & 36.0 & 79,891 & $2,468,956$ & 81,076 \\
\hline LORAZEPAM & $\mathrm{Y}$ & 76.9 & 1,185 & 26,785 & 81,076 \\
\hline FUROSEMIDE & $\mathrm{N}$ & 8.4 & 33,289 & $6,188,582$ & 33,478 \\
\hline FUROSEMIDE & $\mathrm{Y}$ & 19.8 & 190 & 8,977 & 33,478 \\
\hline SODIUM CHLORIDE & $\mathrm{N}$ & 35.0 & 17,917 & 650,140 & 27,337 \\
\hline SODIUM CHLORIDE & $\mathrm{Y}$ & 72.3 & 9,421 & 141,677 & 27,337 \\
\hline CROMOLYN SODIUM & $\mathrm{N}$ & 53.0 & 14,172 & 227,836 & 25,917 \\
\hline CROMOLYN SODIUM & $\mathrm{Y}$ & 55.2 & 11,746 & 225,219 & 25,917 \\
\hline ZOFRAN & $\mathrm{N}$ & 416.9 & 20,641 & 45,407 & $\overline{24,882}$ \\
\hline ZOFRAN & $\mathrm{Y}$ & 331.8 & 4,240 & 30,931 & 24,882 \\
\hline IMMUNE GLOBULIN & $\mathrm{N}$ & 1323.3 & 2,335 & 4,179 & 24,284 \\
\hline IMMUNE GLOBULIN & $\mathrm{Y}$ & 1981.5 & 21,949 & 10,743 & 24,284 \\
\hline FACTOR IX & $\mathrm{Y}$ & 10159.7 & 18,621 & 1,744 & 18,621 \\
\hline TOBRAMYCIN SULFATE & $\mathrm{N}$ & 189.2 & 17,132 & 172,124 & $\overline{18,081}$ \\
\hline TOBRAMYCIN SULFATE & $\mathrm{Y}$ & 261.7 & 949 & 3,707 & 18,081 \\
\hline ACYCLOVIR SODIUM & $\mathrm{N}$ & 75.4 & 16,681 & 366,494 & 16,957 \\
\hline ACYCLOVIR SODIUM & $\mathrm{Y}$ & 734.3 & 277 & 1,161 & 16,957 \\
\hline LUPRON & $\mathrm{N}$ & 1209.6 & 7,153 & 9,819 & $\overline{15,871}$ \\
\hline LUPRON & $\mathrm{Y}$ & 1160.1 & 8,718 & 12,380 & 15,871 \\
\hline CLINDAMYCIN PHOSPHATE & $\mathrm{N}$ & 53.5 & 13,040 & 324,187 & 13,462 \\
\hline CLINDAMYCIN PHOSPHATE & $\mathrm{Y}$ & 150.7 & 422 & 3,337 & 13,462 \\
\hline VANCOMYCIN HYDROCHLORIDE & $\mathrm{N}$ & 184.4 & 3,474 & 16,676 & 13,365 \\
\hline VANCOMYCIN HYDROCHLORIDE & $\mathrm{Y}$ & 194.3 & 9,892 & 45,095 & 13,365 \\
\hline CIMETIDINE HYDROCHLORIDE & $\mathrm{N}$ & 21.2 & 11,690 & 664,202 & 11,706 \\
\hline CIMETIDINE HYDROCHLORIDE & $\mathrm{Y}$ & 45.6 & 16 & 521 & 11,706 \\
\hline DIAZEPAM & $\mathrm{N}$ & 24.2 & 11,119 & $1,083,068$ & 11,141 \\
\hline DIAZEPAM & $\mathrm{Y}$ & 15.2 & 22 & 1,331 & 11,141 \\
\hline CALCITRIOL & $\mathrm{N}$ & 97.4 & 8,906 & 136,094 & 9,263 \\
\hline CALCITRIOL & $\mathrm{Y}$ & 290.1 & 358 & 24,056 & 9,263 \\
\hline METHOTREXATE SODIUM & $\mathrm{N}$ & 38.2 & 9,014 & 173,751 & 9,261 \\
\hline METHOTREXATE SODIUM & $\mathrm{Y}$ & 17.4 & 247 & 20,216 & 9,261 \\
\hline KYTRIL & $\mathrm{N}$ & 606.3 & 4,206 & 7,812 & 6,780 \\
\hline KYTRIL & $\mathrm{Y}$ & 786.5 & 2,575 & 12,653 & 6,780 \\
\hline DEXTROSE & $\mathrm{N}$ & 57.6 & 483 & 9,476 & 6,246 \\
\hline DEXTROSE & $\mathrm{Y}$ & 70.2 & 5,764 & 105,501 & 6,246 \\
\hline AMPHOTERICIN B & $\mathrm{N}$ & 839.2 & 5,253 & 5,400 & 6,027 \\
\hline AMPHOTERICIN B & $\mathrm{Y}$ & 120.6 & 774 & 2,634 & 6,027 \\
\hline HEPARIN LOCK FLUSH & $\mathrm{N}$ & 39.7 & 3,665 & 139,014 & 4,506 \\
\hline HEPARIN LOCK FLUSH & $\mathrm{Y}$ & 15.1 & 841 & 62,470 & 4,506 \\
\hline METAPROTERENOL SULFATE & $\mathrm{N}$ & 26.7 & 3,365 & 134,173 & 4,181 \\
\hline METAPROTERENOL SULFATE & $\mathrm{Y}$ & 55.1 & 816 & 12,522 & 4,181 \\
\hline GENTAMICIN SULFATE & $\mathrm{N}$ & 17.6 & 3,639 & 340,752 & 3,737 \\
\hline GENTAMICIN SULFATE & $\mathrm{Y}$ & 28.0 & 98 & 4,477 & 3,737 \\
\hline WINRHO SDF & $\mathrm{Y}$ & 2080.4 & 3,696 & 3,162 & 3,696 \\
\hline LEUCOVORIN CALCIUM & $\mathrm{N}$ & 166.3 & 2,536 & 21,744 & 3,256 \\
\hline LEUCOVORIN CALCIUM & $\mathrm{Y}$ & 322.1 & 720 & 3,039 & 3,256 \\
\hline ANZEMET/DOLASETRON MESYLATE & $\mathrm{N}$ & 658.8 & 779 & 1,349 & 3,007 \\
\hline ANZEMET/DOLASETRON MESYLATE & $\mathrm{Y}$ & 341.4 & 2,227 & 49,613 & 3,007 \\
\hline CYCLOPHOSPHAMIDE & $\mathrm{N}$ & 123.8 & 1,348 & 8,444 & 2,690 \\
\hline CYCLOPHOSPHAMIDE & $\mathrm{Y}$ & 930.0 & 1,342 & 4,092 & 2,690 \\
\hline DOXORUBICIN HYDROCHLORIDE & $\mathrm{N}$ & 703.1 & 721 & 703 & 2,461 \\
\hline DOXORUBICIN HYDROCHLORIDE & $\mathrm{Y}$ & 356.0 & 1,740 & 4,641 & 2,461 \\
\hline
\end{tabular}




\begin{tabular}{|c|c|c|c|c|c|}
\hline Generic Drug Group & $\begin{array}{c}\text { Targeted by } \\
\text { DOJ? }\end{array}$ & $\begin{array}{c}\text { Mean } \\
\text { Reimbursement } \\
\text { per Prescription } \\
\end{array}$ & $\begin{array}{c}\text { Total Medicaid } \\
\text { Reimbursement } \\
\text { Amount (\$1000s) } \\
\end{array}$ & $\begin{array}{c}\text { Total Number of } \\
\text { Prescriptions }\end{array}$ & $\begin{array}{c}\text { Total Reimbursement } \\
\text { Amount for Drug } \\
\text { Group ( } \$ 1000 \text { s) } \\
\end{array}$ \\
\hline ACETYLCYSTEINE & $\mathrm{N}$ & 72.5 & 874 & 12,852 & 2,081 \\
\hline ACETYLCYSTEINE & $\mathrm{Y}$ & 76.9 & 1,207 & 15,538 & 2,081 \\
\hline ETOPOSIDE & $\mathrm{N}$ & 617.7 & 1,725 & 2,488 & 2,074 \\
\hline ETOPOSIDE & $\mathrm{Y}$ & 326.5 & 349 & 1,064 & 2,074 \\
\hline DEXAMETHASONE & $\mathrm{N}$ & 14.6 & 2,025 & 144,932 & 2,063 \\
\hline DEXAMETHASONE & $\mathrm{Y}$ & 15.0 & 38 & 2,731 & 2,063 \\
\hline IRON DEXTRAN & $\mathrm{N}$ & 127.4 & 317 & 2,614 & 1,898 \\
\hline IRON DEXTRAN & $\mathrm{Y}$ & 165.1 & 1,581 & 11,768 & 1,898 \\
\hline $\begin{array}{l}\text { CISPLATIN } \\
\end{array}$ & $\mathrm{N}$ & 614.0 & 1,160 & 1,976 & 1,160 \\
\hline CISPLATIN & $\mathrm{Y}$ & 720.8 & 1 & 1 & 1,160 \\
\hline AMIKACIN SULFATE & $\mathrm{N}$ & 329.2 & 288 & 739 & $\overline{1,146}$ \\
\hline AMIKACIN SULFATE & $\mathrm{Y}$ & 389.1 & 859 & 3,100 & 1,146 \\
\hline FLUOROURACIL & $\mathrm{N}$ & 61.5 & 1,090 & 15,166 & 1,139 \\
\hline FLUOROURACIL & $\mathrm{Y}$ & 27.5 & 50 & 3,338 & 1,139 \\
\hline METHYLPREDNISOLONE SODIUM SUCCINATE & $\mathrm{N}$ & 32.6 & 640 & 23,669 & 1,064 \\
\hline METHYLPREDNISOLONE SODIUM SUCCINATE & $\mathrm{Y}$ & 51.8 & 424 & 9,749 & 1,064 \\
\hline TESTOSTERONE CYPIONATE & $\mathrm{N}$ & 41.3 & 51 & 1,286 & 938 \\
\hline TESTOSTERONE CYPIONATE & $\mathrm{Y}$ & 50.6 & 887 & 15,208 & 938 \\
\hline PENTAMIDINE ISETHIONATE & $\mathrm{N}$ & 165.4 & 629 & 5,647 & 816 \\
\hline PENTAMIDINE ISETHIONATE & $\mathrm{Y}$ & 203.4 & 188 & 1,099 & 816 \\
\hline ANTI-INHIBITOR COAGULANT COMPLEX & $\mathrm{N}$ & 9135.9 & 62 & 12 & 743 \\
\hline ANTI-INHIBITOR COAGULANT COMPLEX & $\mathrm{Y}$ & 16368.5 & 680 & 51 & 743 \\
\hline BLEOMYCIN SULFATE & $\mathrm{Y}$ & 713.5 & 684 & 791 & $\overline{684}$ \\
\hline TESTOSTERONE ENANTHATE & $\mathrm{N}$ & 57.0 & 438 & 6,268 & 452 \\
\hline TESTOSTERONE ENANTHATE & $\mathrm{Y}$ & 27.8 & 14 & 503 & 452 \\
\hline VINCRISTINE SULFATE & $\mathrm{N}$ & 77.8 & 48 & 644 & $\overline{150}$ \\
\hline VINCRISTINE SULFATE & $\mathrm{Y}$ & 59.8 & 101 & 1,887 & 150 \\
\hline MITOMYCIN & $\mathrm{N}$ & 430.8 & 103 & 163 & $\overline{148}$ \\
\hline MITOMYCIN & $\mathrm{Y}$ & 535.0 & 45 & 93 & 148 \\
\hline HYDROCORTISONE SODIUM SUCCINATE & $\mathrm{N}$ & 23.3 & 35 & 1,668 & 99 \\
\hline HYDROCORTISONE SODIUM SUCCINATE & $\mathrm{Y}$ & 23.8 & 65 & 3,281 & 99 \\
\hline CYTARABINE & $\mathrm{Y}$ & 95.7 & 76 & 1,188 & 76 \\
\hline VINBLASTINE SULFATE & $\mathrm{N}$ & 135.6 & 12 & 171 & 48 \\
\hline VINBLASTINE SULFATE & $\mathrm{Y}$ & 51.3 & 36 & 1,068 & 48 \\
\hline
\end{tabular}

Notes: The sample excludes data from the five states that do not use the AWP as their primary reimbursement methodology and outliers as described in the text in section 4.2. 